\title{
Highly Efficient 1-Octene Hydroformylation at Low Syngas Pressure: From Single-Droplet Screening to Continuous Flow Synthesis
}

Keshav Raghuvanshi, ${ }^{a}$ Cheng Zhu, ${ }^{a}$ Mahdi Ramezani, ${ }^{a}$ Stefano Menegatti, ${ }^{a}$ Erik E. Santiso, ${ }^{a}$ Dawn Mason, ${ }^{\mathrm{b}}$ Jody Rodgers, ${ }^{\mathrm{b}}$ Mesfin E. Janka, ${ }^{\mathrm{b}}$ and Milad Abolhasani*a

\footnotetext{
[a] Department of Chemical and Biomolecular Engineering North Carolina State University 911 Partners Way, Raleigh, NC 27695 USA E-mail: abolhasani@ncsu.edu Webpage: www.abolhasanilab.com

[b] Eastman Chemical Company, Technology, 200 S. Wilcox Dr., Kingsport, TN 37660, USA
}

\section{Table of Contents}

\section{S1. Flow Chemistry Platforms}

S1.1 Continuous Flow Chemistry Platform

S1.2 Control Continuous Flow Chemistry Platform

\section{S2. Experimental Methods}

S2.1 Analytical Methods 


\section{S1. Flow Chemistry Platforms}

\section{S1.1 Continuous Flow Chemistry Platform}

Reagents were prepared according to the general procedure reported in Section $\mathbf{S 2 . 2}$ in $20 \mathrm{~mL}$ vials under inert atmosphere and were delivered to the continuous flow reactor using two syringe-free M6 Pumps (VICI, 2-4841-F1-KZ). Fluoropolymer tubing (fluorinated ethylene propylene, FEP, IDEX health \& sciences) was used to connect the reagent reservoirs to the pump inlets and the pump outlets to a T-junction for mixing the reagents before entering the tube-in-tube flow reactor. The liquid and gas lines were connected to the continuous flow reactor using Swagelok fittings. The custom-designed tube-in-tube flow reactor consists of a Teflon AF2400 tubing (0.04" O.D. and 0.032" I.D., Biogeneral) inserted inside a Fluorinated ethylene propylene (FEP) tubing (1/8" O.D and 1/16" I.D., Altaflo), sandwiched between two CNC-machined aluminum plates (Fig. S1). As shown in Fig. S1, the reactor was designed in a way that the gas flow was contained in the outer annulus of the tube-in-tube flow reactor and the fluid flows inside the inner Teflon AF tubing. A thermocouple (K type, Omega), a temperature controller (CN9311, Omega), and eight cartridge heaters (Omega) were used to automatically heat the flow reactor and maintain the desired reaction temperature. Syngas flow rate and composition was controlled using separate $\mathrm{H}_{2}$ and $\mathrm{CO}$ mass flow controllers (EL-Flow, Bronkhorst) and a back pressure regulator (EL-PRESS, Bronkhorst), remotely controlled by an in-house developed LabVIEW code.

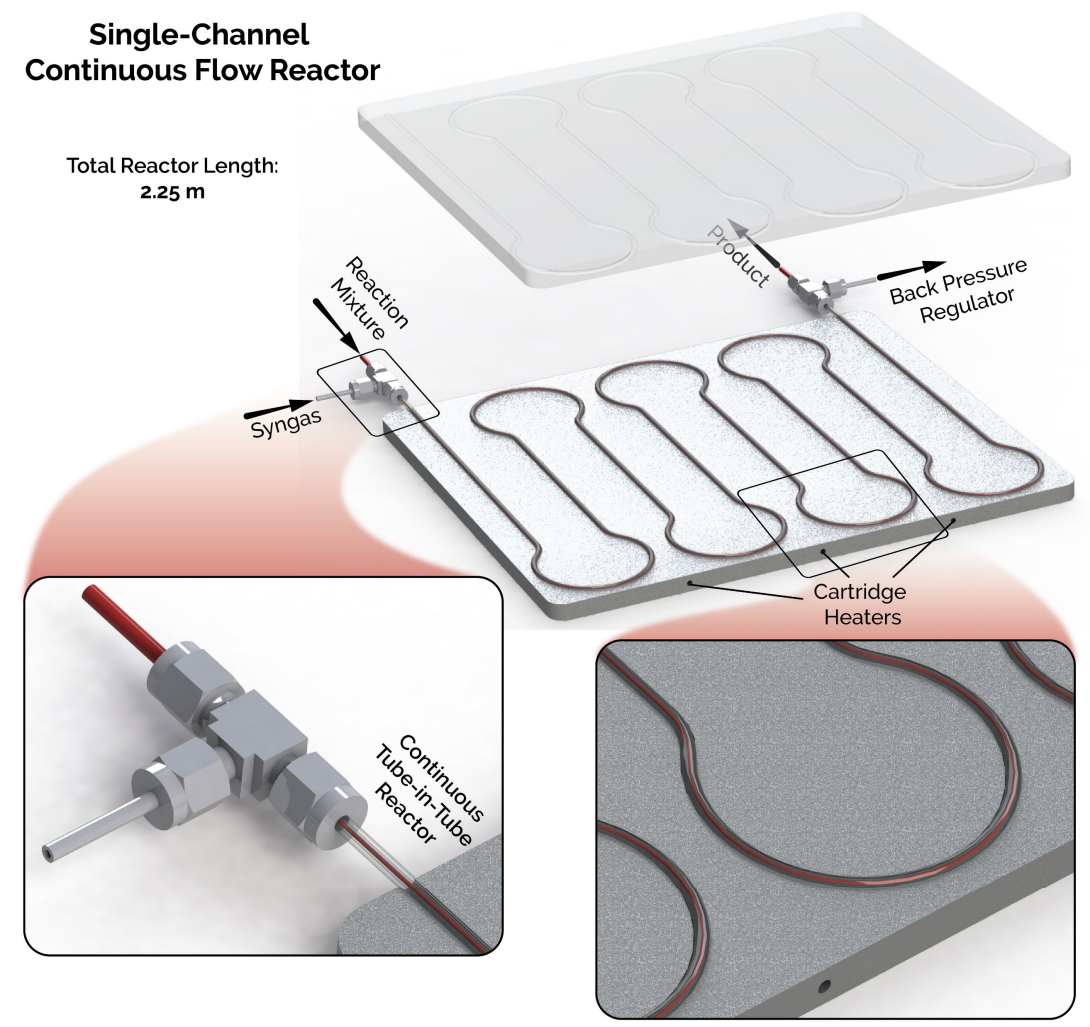

Figure S1: Rendered schematic of the continuous flow reactor sandwiched between two CNC-machined aluminum plates. 
An automated sampling module was designed and integrated with the continuous flow reactor for an automatic sample injection into the analytical characterization module (HPLC/ELSD/MS). Upon reaching steady-state condition (2 residence times delay time), a 6-port, 2position Rheodyne valve (MXP7900-000, IDEX H\&S) was automatically triggered to fill out the sample loop $(5 \mu \mathrm{L})$ as shown in Fig. $\mathbf{S 2}$ before switching back to inject the sample into the HPLC unit for analysis. The remainder of the reaction mixture was collected in a custom-designed stainless-steel pressurized vessel for offline analysis.

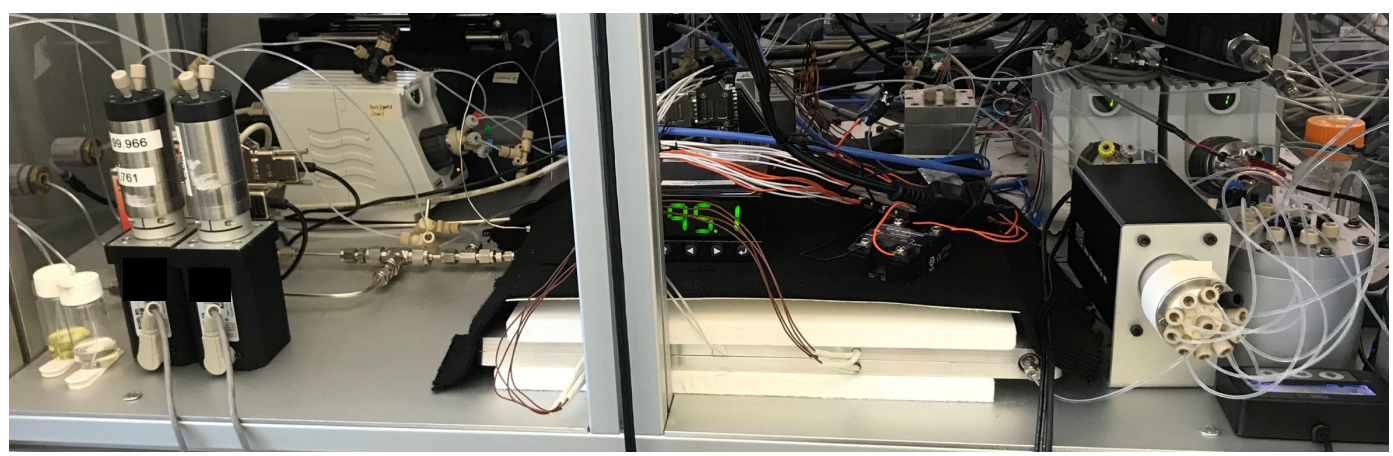

Figure S2: Continuous flow reactor enclosed within a shatter-resistant enclosure.

The developed continuous flow reactor was placed in a custom-designed enclosure for safe operation as the hydroformylation reaction setup involves using toxic and combustible gases $\left(\mathrm{CO}\right.$ and $\left.\mathrm{H}_{2}\right)$. The enclosure was vented through an exhaust port at the top of the enclosure. The enclosure was constructed out of aluminum framing with Lexan windows (MiniTec Framing Systems). Lexan (Fig. S3) is shatter resistant to ensure researcher safety in the unlikely event of an explosion within the enclosure

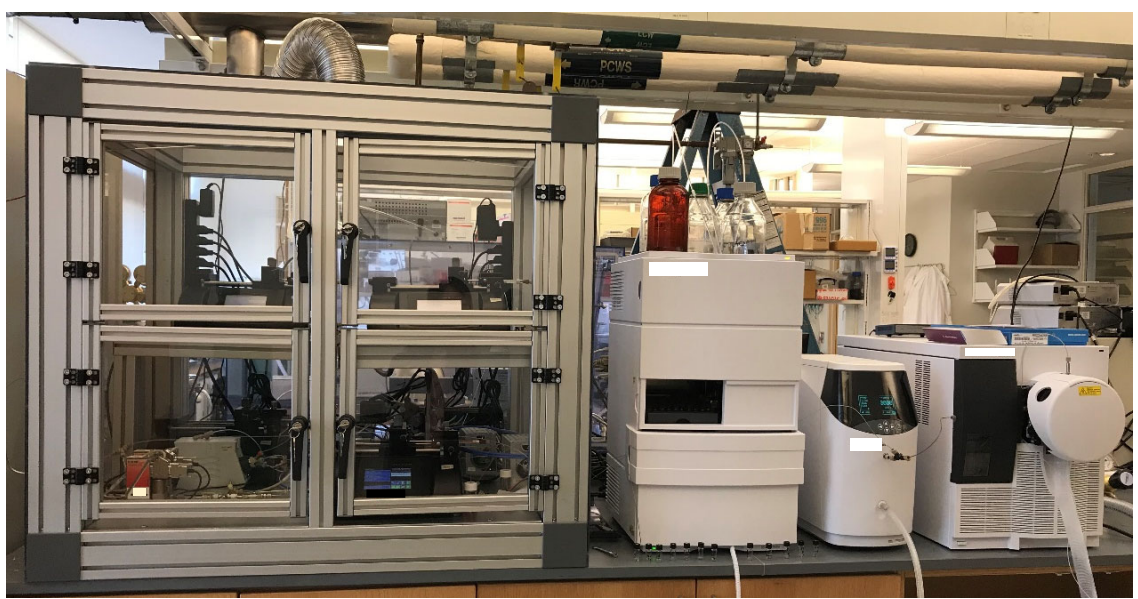

Figure S3: The custom-built enclosure and the HPLC/MS/ELSD analysis units. 


\section{S1.2 Control Continuous Flow Chemistry Platform}

In order to evaluate the effect of oxygen permeability through the outer FEP tubing on the hydroformylation reaction, a control experiment using a stainless-steel outer tubing (Fig. S4) was conducted. The results of the stainless steel continuous flow reactor (Fig. S5) showed similar reactivity to the FEP outer tubing.

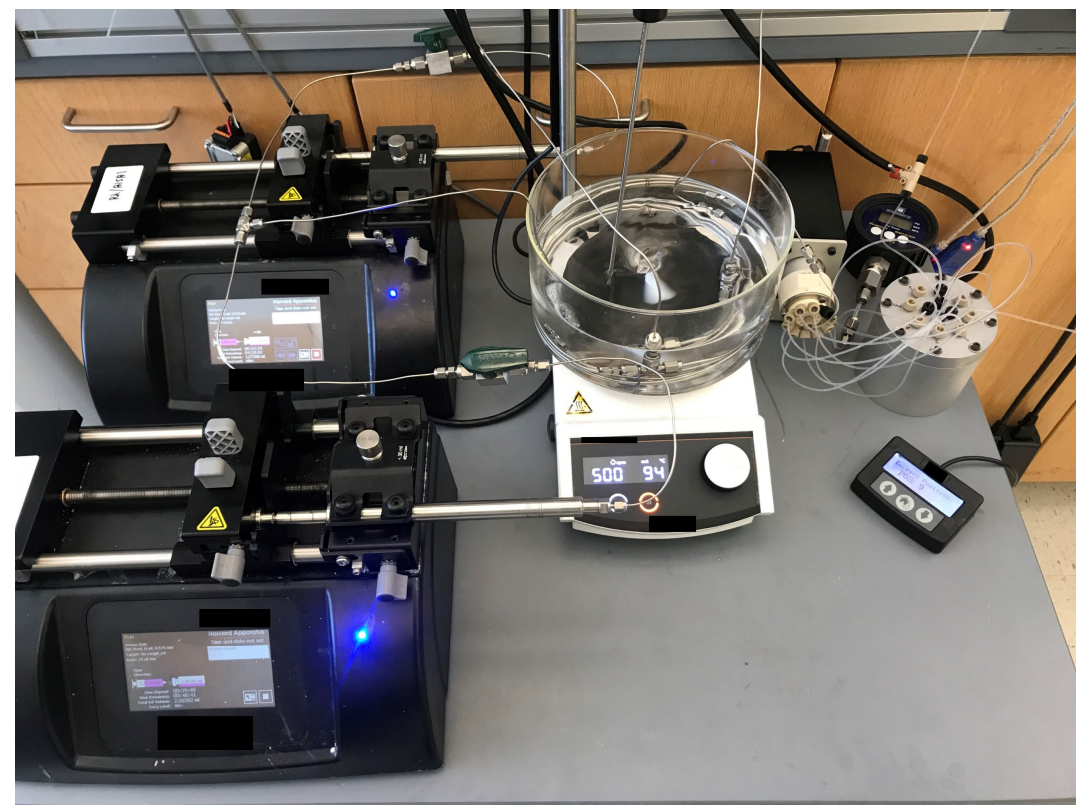

Figure S4: Control continuous flow chemistry setup with stainless steel outer tubing.

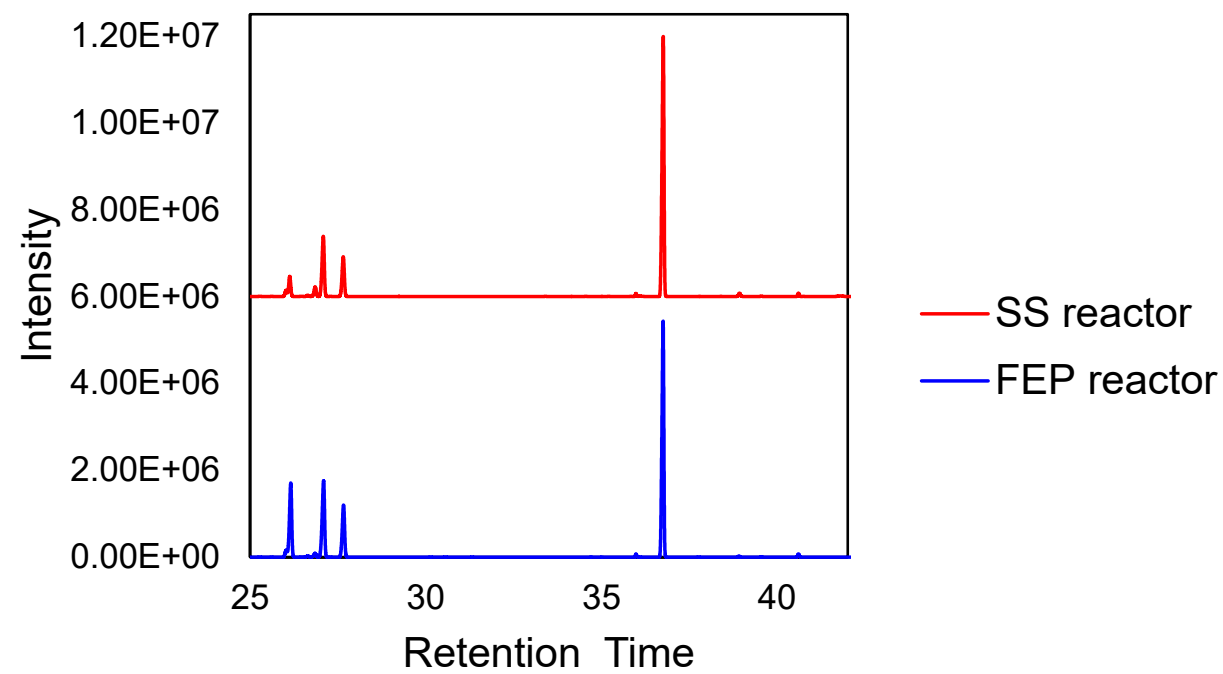

Figure S5: GC chromatograms of the product (2-methyloctanal) from stainless steel reactor and FEP reactor operated at 50 psig syngas pressure $\left(1: 1, \mathrm{CO}: \mathrm{H}_{2}\right)$. 


\section{S2. Experimental Methods}

\section{S2.1 Analytical Methods}

Quantification of the single-droplet screening hydroformylation products were performed via liquid chromatography (Agilent 1220 Infinity HPLC) coupled with light scattering detector (1260 Infinity ELSD) and mass spectrometer (6120 Single Quadrupole MS). $5 \mu \mathrm{L}$ sample was injected into a HPLC/ELSD/MS analytical unit with water/THF mobile phase. Alkene and aldehyde isomers were successfully separated by a reverse phase column (Agilent Poroshell 120 EC-C18, 4.6 x 150 mm, 2.7 $\mu \mathrm{m})$ and quantified by a Diode Array Detector (DAD). Products were identified by comparing retention times of analytes to those of pure standards using HPLC. Analysis of continuous flow and batch hydroformylation products were conducted using a gas chromatography (Shimadzu GC-2010) unit equipped with a flame ionization detector (FID). The hydroformylation products were separated using a non-polar column (Agilent J\&W DB-1, $60 \mathrm{~m} \times 0.32 \mathrm{~mm}, 1.0 \mu \mathrm{m}$ ). Products were identified by comparing retention times of analytes to those of pure standards using GC-FID.

Chemicals. $\left[\mathrm{Rh}(\mathrm{CO})_{2}(\mathrm{acac})\right]$ was purchased from Strem Chemicals as a catalyst precursor, Anhydrous toluene (DriSolv Toluene, 99.8\%, EMD Millipore) was purchased from Milipore-Sigma. BISBI ligand was provided by Eastman Chemical Company. We used 1,3,5-trimethoxybenzene (99\%, Sigma Aldrich) as the internal standard for product analysis and 1-octene (98\%, Sigma Aldrich) as the hydroformylation substrate. Certified gas mixture $\left(\mathrm{H}_{2}\right.$ : Ultra High Purity $5.0 \mathrm{Grade}$; $\mathrm{CO}: 25 \% \mathrm{H}_{2}$ Balance $\mathrm{CO}$ ) and nitrogen ( $\mathrm{N}_{2}$ : Ultra High Purity 5.0 Grade) were purchased from Airgas 


\section{S2.2 General Procedure for Sample Preparation}

Catalyst Stock Solution: An oven-dried $2.0 \mathrm{~mL}$ vial equipped with fitted Teflon septum, was charged with $\mathrm{Rh}(\mathrm{acac})(\mathrm{CO})_{2}$ $(1.03 \mathrm{mg})$ in glove box and anhydrous toluene $(1.98 \mathrm{~mL})$ was subsequently added to form a clear solution. The vial was then transferred to isolation glovebox as part of the hydroformylation setup.

Substrate Stock Solution: An oven-dried $20 \mathrm{~mL}$ vial equipped with Teflon septum, was charged with freshly distilled 1-octene $(1.60 \mathrm{~mL})$ and anhydrous toluene $(8.40 \mathrm{~mL})$ in a glove box. The vial was then transferred to isolation glovebox as part of the hydroformylation setup.

Ligand Stock Solution: An oven-dried $20 \mathrm{~mL}$ vial equipped with Teflon septum, was charged with BISBI (16.7 mg) and anhydrous toluene $(8.40 \mathrm{~mL})$ in a glove box. The vial was then transferred to isolation glovebox.

Quench Stock Solution: An oven-dried $20 \mathrm{~mL}$ vial equipped with Teflon septum, was charged with 1,3,5-trimethoxybenzene $(16.90 \mathrm{mg})$ and acetonitrile $(10.0 \mathrm{~mL})$. The vial was then transferred to isolation glovebox. 
S2.3: Styrene and Aldehydes Calibration

A

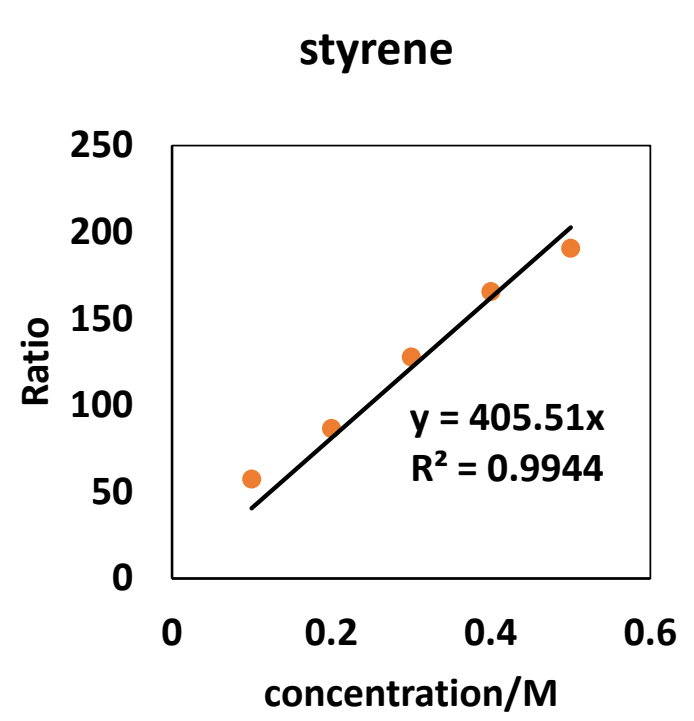

C

\section{2-phenylpropionaldehyde}

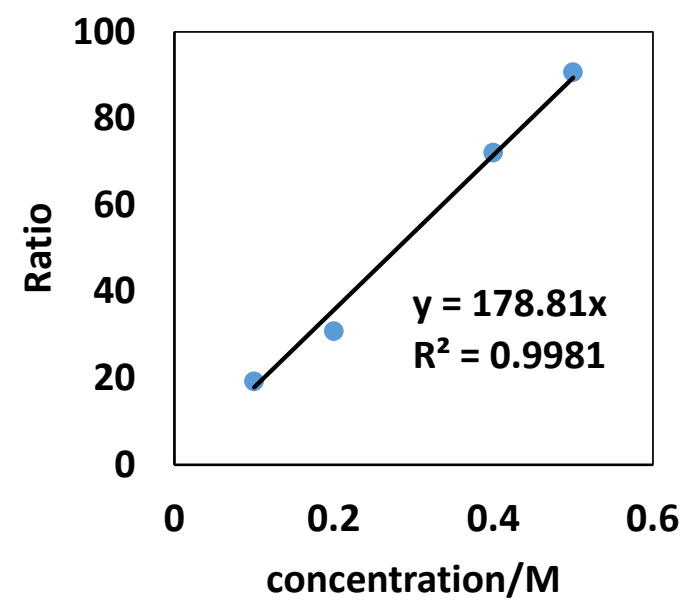

B

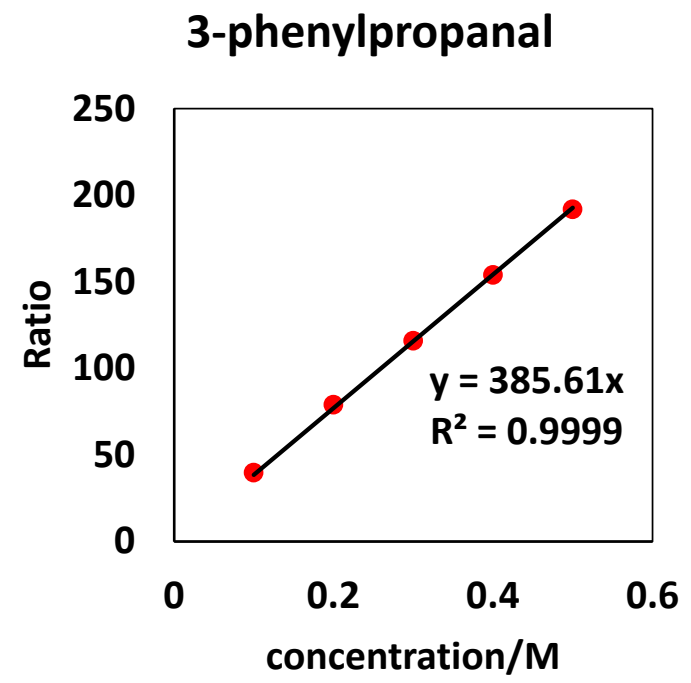

Figure S6: GC calibration curves for (A) Styrene, (B) 3-Phenylpropanaldehyde, and (C) 2-Phenylpropanaldehyde. 
S3. NMR Characterizations of BISBI and Hydroformylation Products

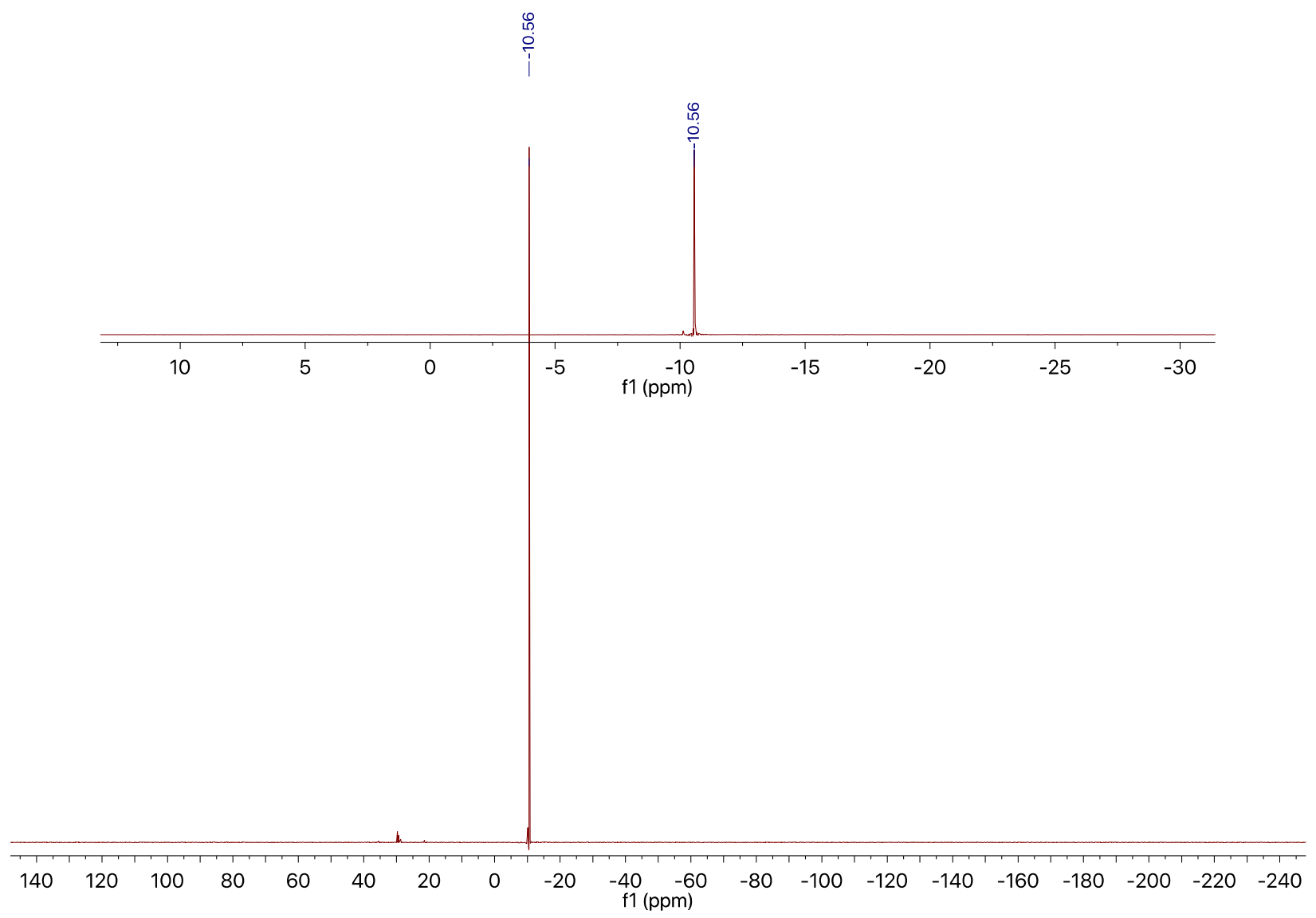

Figure S7: ${ }^{31} \mathrm{P}$ NMR (243 $\mathrm{MHz}$ in $\left.\mathrm{CDCl}_{3}\right)$ analysis of $\mathrm{BISBI}$. 


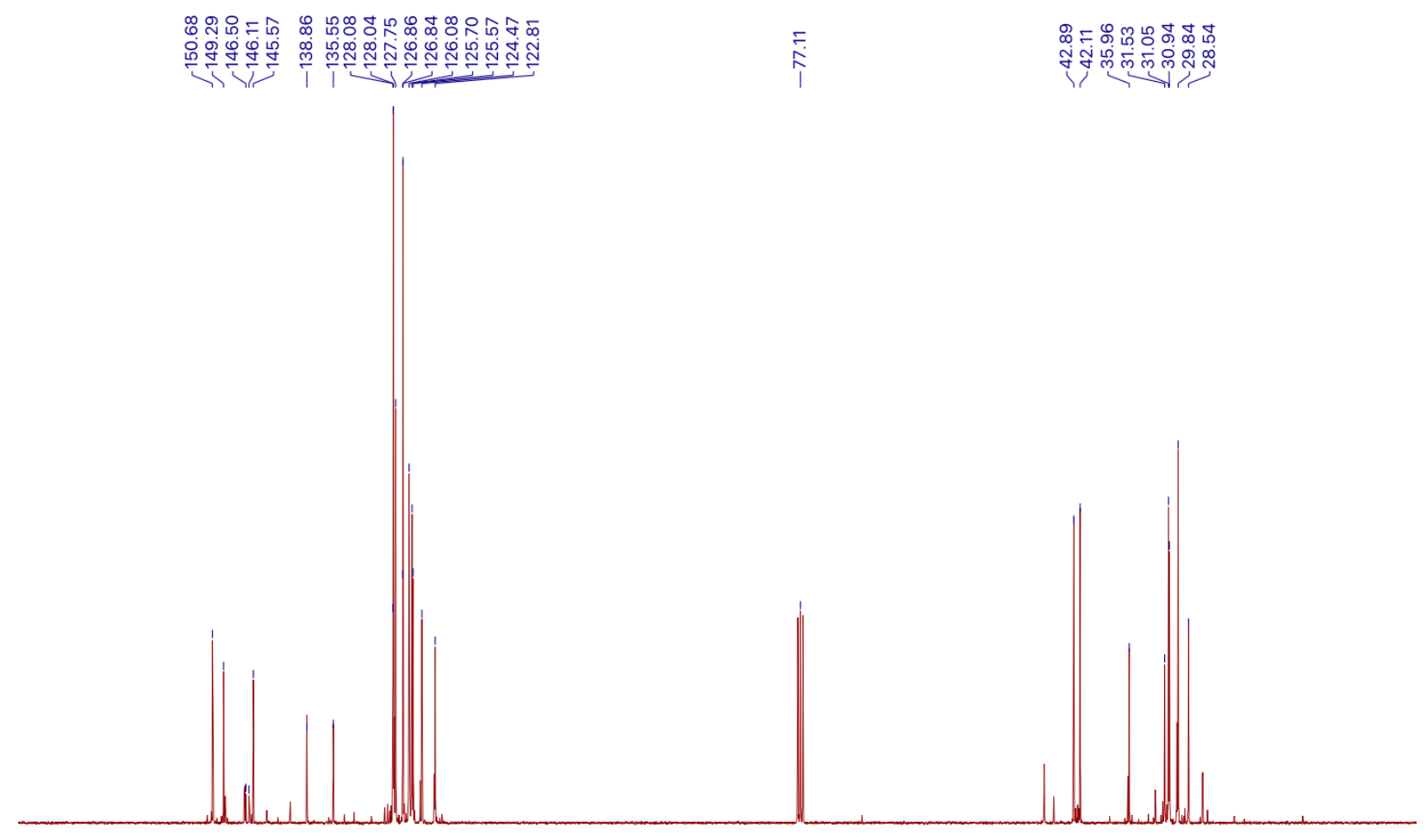

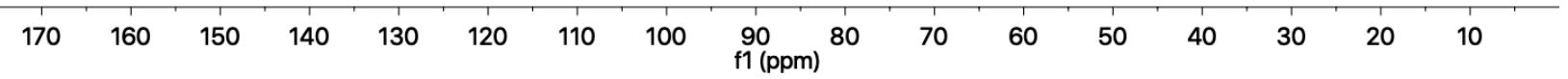

Figure S8: ${ }^{13} \mathrm{C} \mathrm{NMR}\left(600 \mathrm{MHz}\right.$ in $\left.\mathrm{CDCl}_{3}\right)$ analysis of $\mathrm{BISBI}$. 


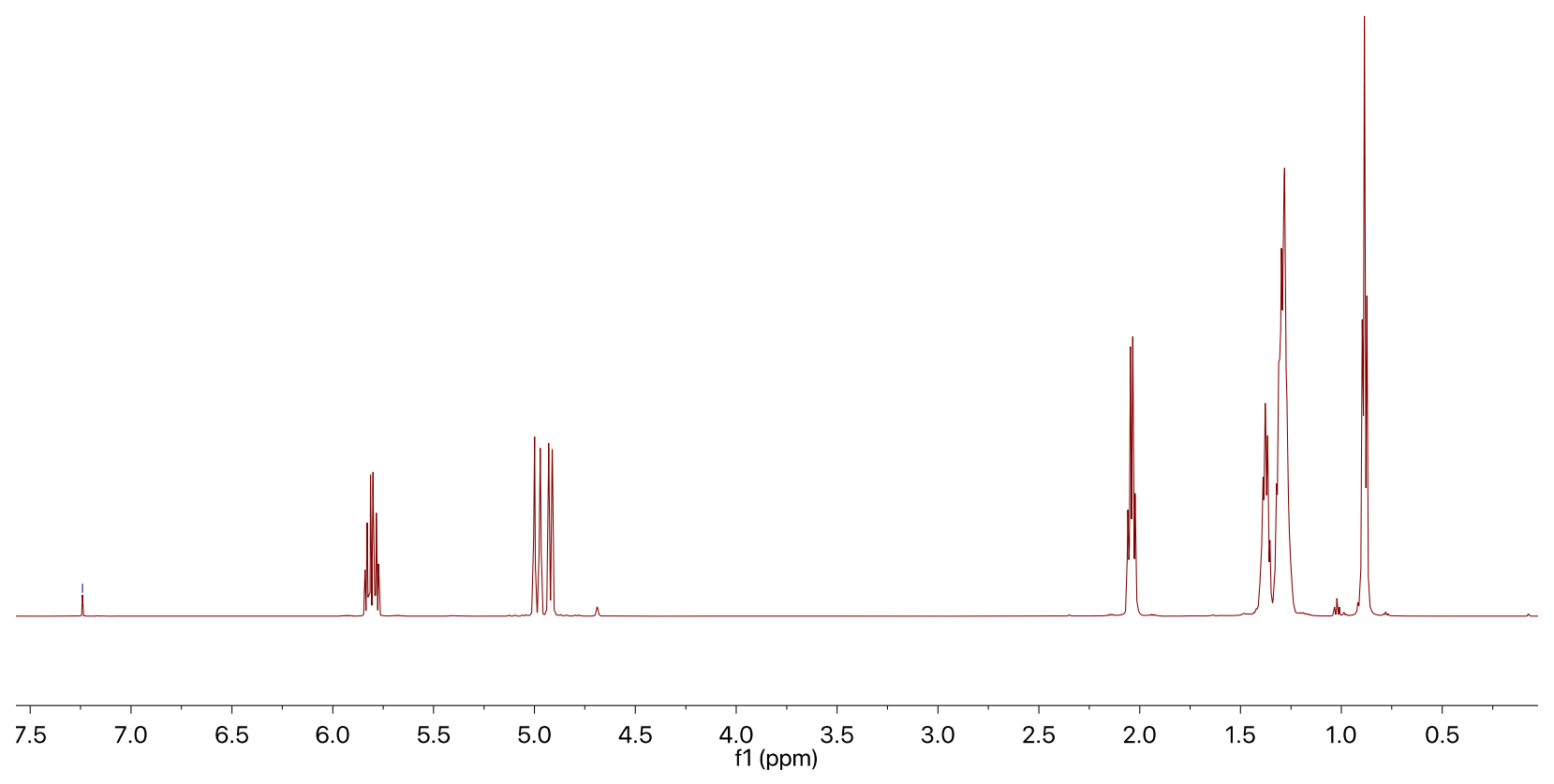

Figure S9: ${ }^{1} \mathrm{H} \mathrm{NMR}\left(700 \mathrm{MHz}\right.$ in $\left.\mathrm{CDCl}_{3}\right)$ analysis of purified 1-octene.

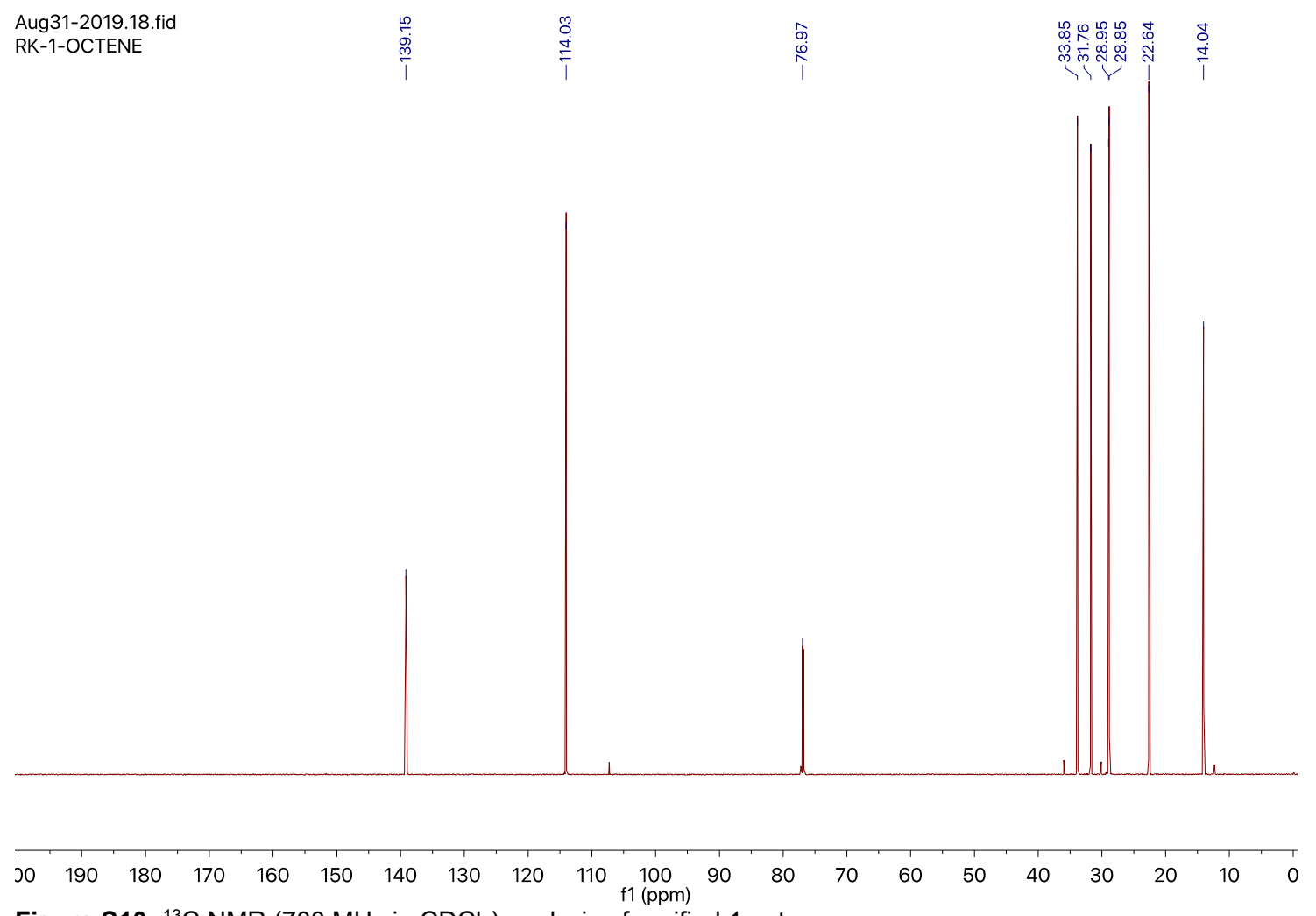

Figure S10: ${ }^{13} \mathrm{C} \mathrm{NMR}\left(700 \mathrm{MHz}\right.$ in $\left.\mathrm{CDCl}_{3}\right)$ analysis of purified 1-octene. 


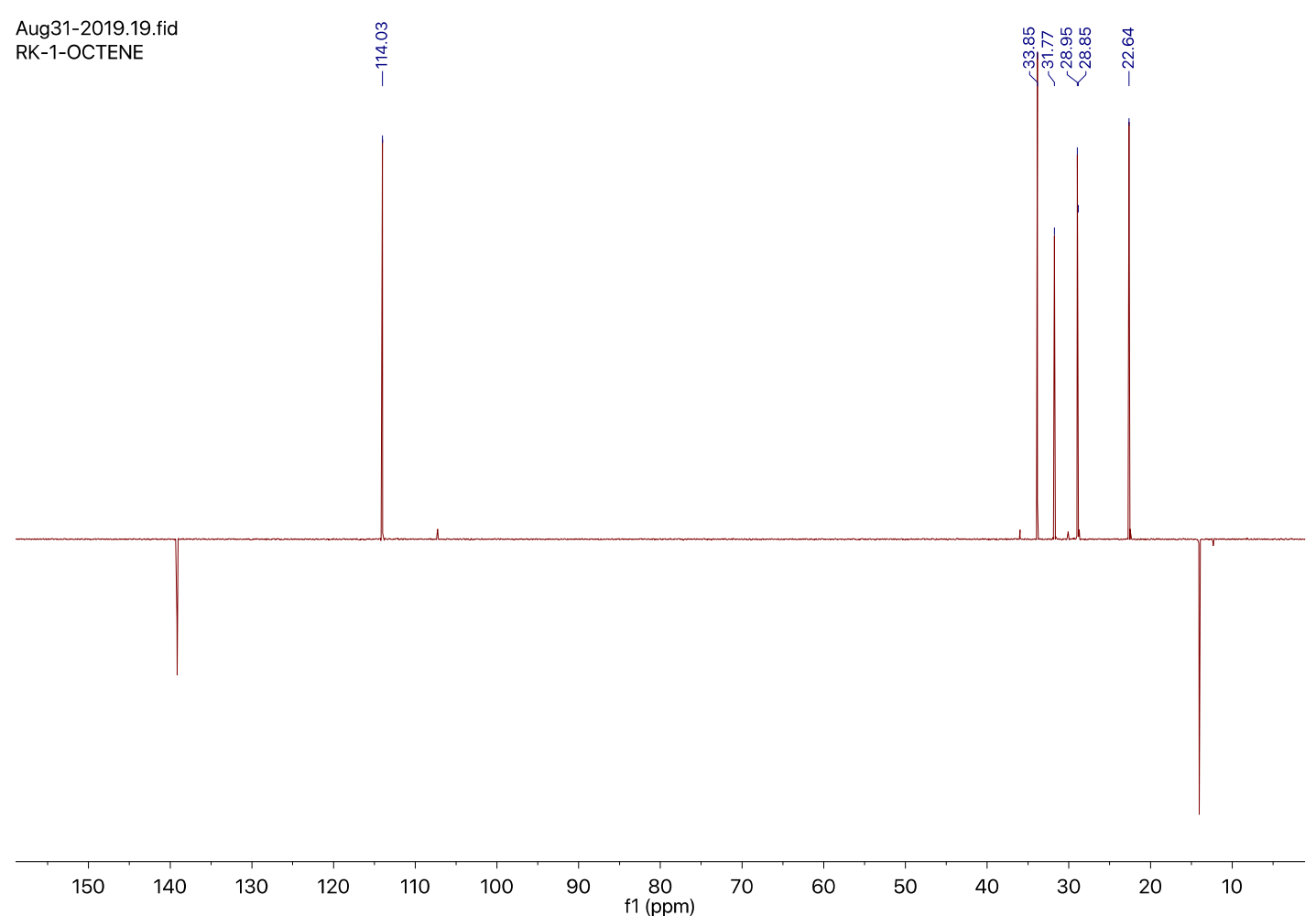

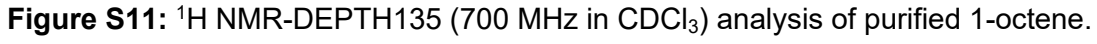

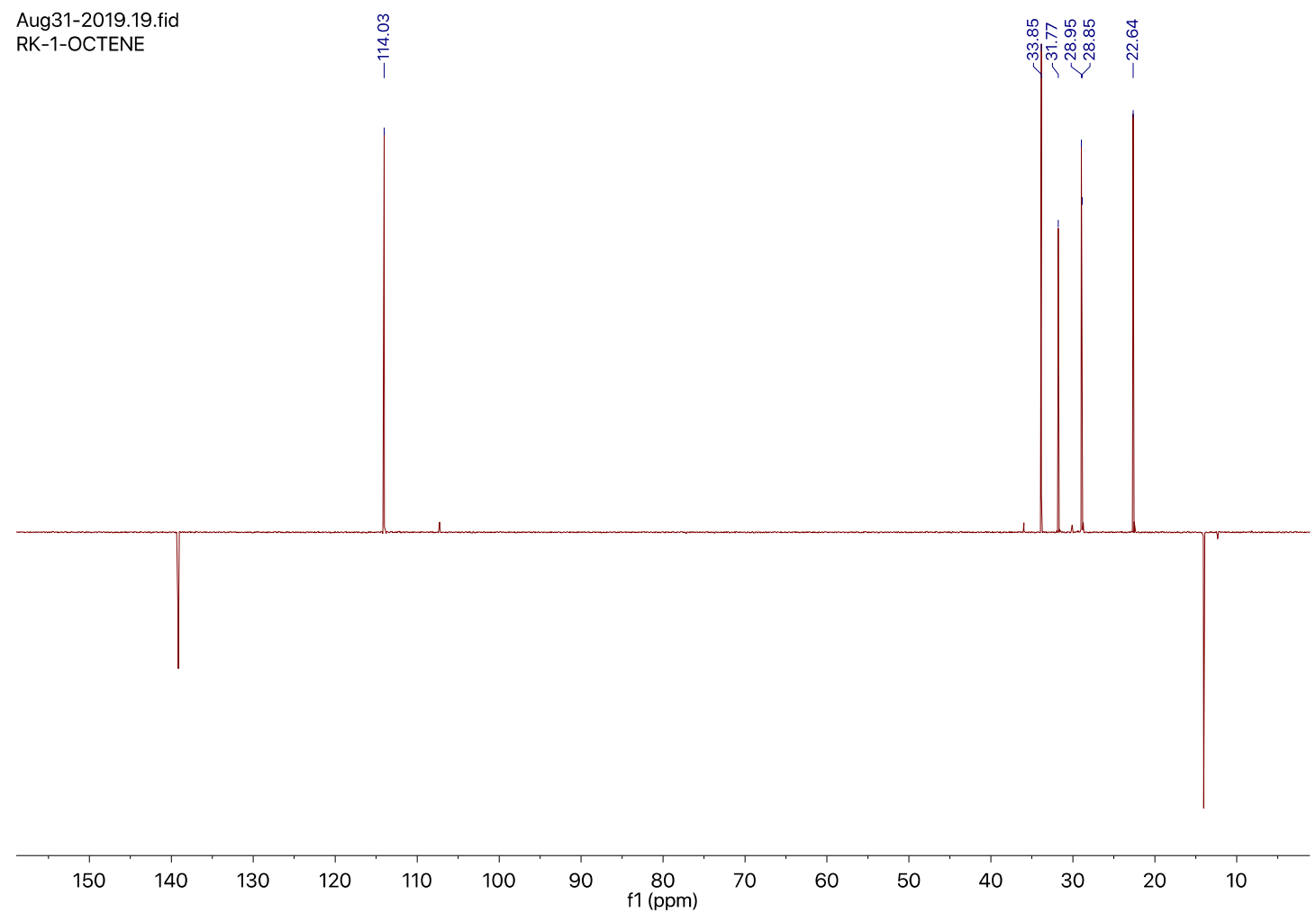

Figure S12: ${ }^{1} \mathrm{H}$ NMR-DEPTH90 (700 MHz in $\left.\mathrm{CDCl}_{3}\right)$ analysis of purified 1-octene. 


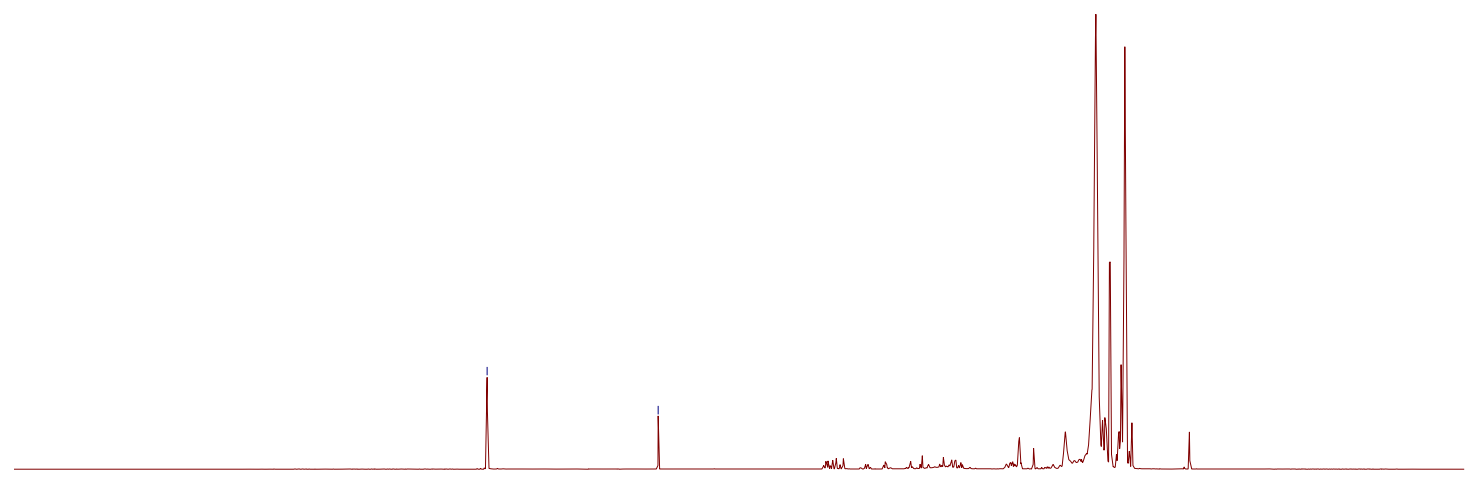

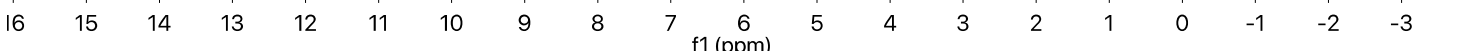

Figure S13: ${ }^{1} \mathrm{H}$ NMR-APT ( $175 \mathrm{MHz}$ in $\mathrm{CDCl}_{3}$ ) analysis of purified 2-methyl-octanal.

Aug31-2019.30.fid 2-METIIIYL-OCTANAL
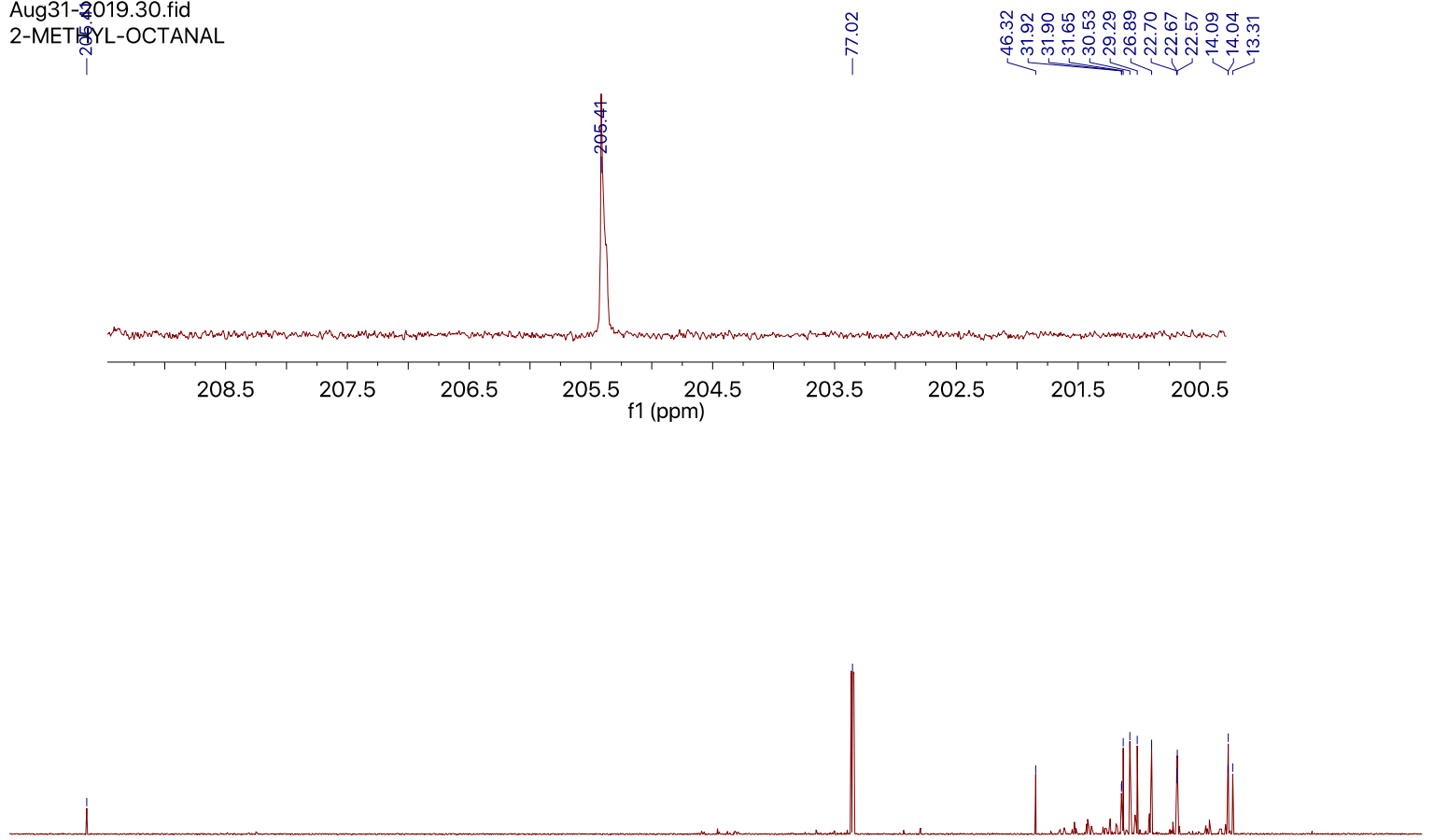

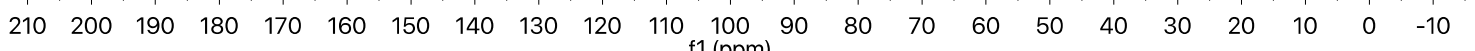

Figure S14: ${ }^{13} \mathrm{C}$ NMR-APT (175 $\mathrm{MHz}$ in $\mathrm{CDCl}_{3}$ ) analysis of purified 2-methyl-octanal. 

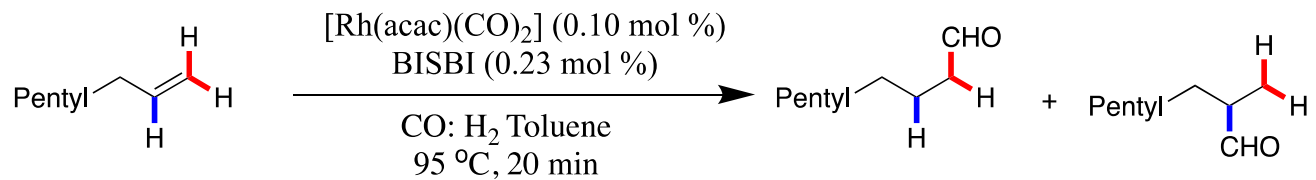

Scheme S1: Rh-catalyzed hydroformylation of 1-octene

rk-ch-01-conti.10.fid

rk-ch-01-conti
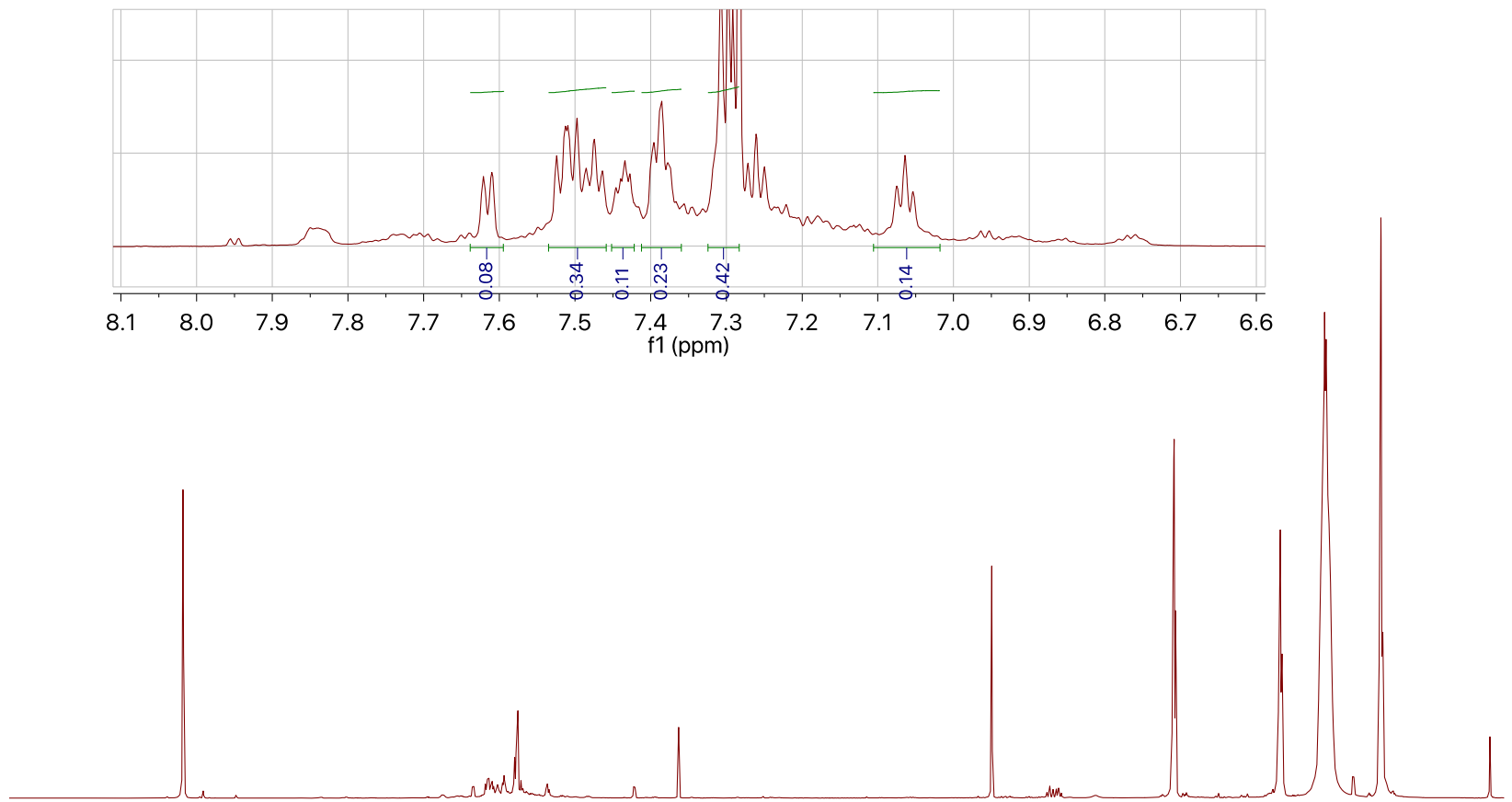

$\begin{array}{lllllllllllllllllllllll}1.0 & 10.5 & 10.0 & 9.5 & 9.0 & 8.5 & 8.0 & 7.5 & 7.0 & 6.5 & 6.0 \underset{\mathrm{f} 1}{(\mathrm{ppm})} & 5.0 & 4.5 & 4.0 & 3.5 & 3.0 & 2.5 & 2.0 & 1.5 & 1.0 & 0.5 & 0 .\end{array}$

Figure S15: Crude ${ }^{1} \mathrm{H}$ NMR $\left(700 \mathrm{MHz}\right.$ in $\left.\mathrm{CDCl}_{3}\right)$ analysis of Rh-catalyzed hydroformylation of 1-octene. 
rk-ch-01-conti.11.fid

rk-ch-01-conti

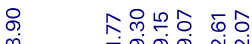

C13DEPT135

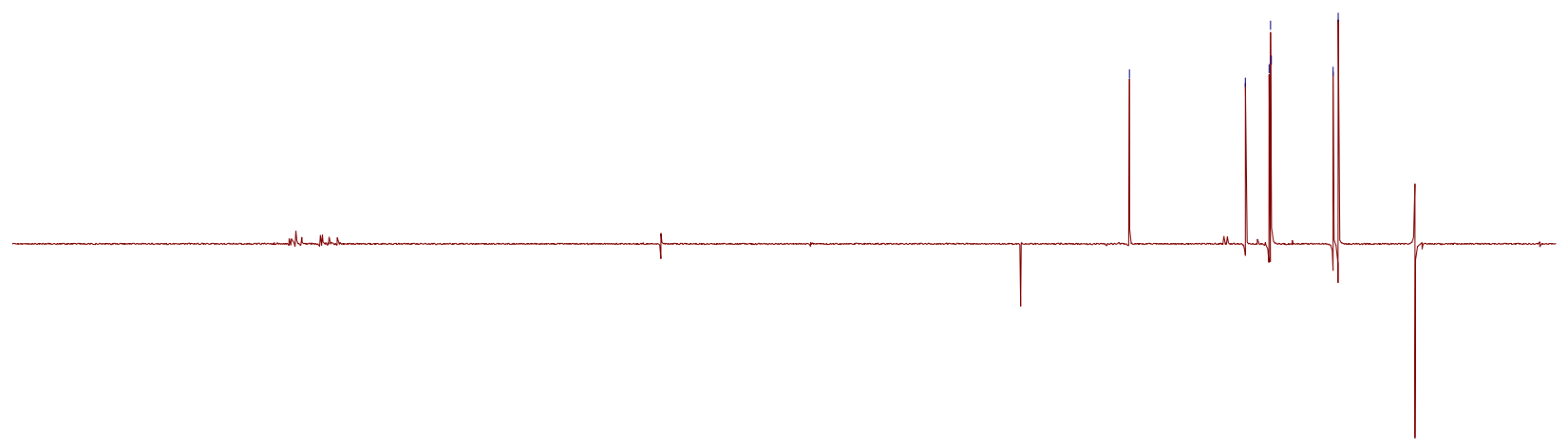

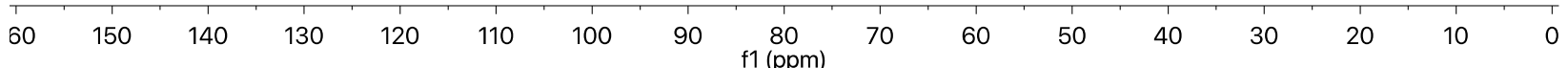

Figure S16: Crude ${ }^{13} \mathrm{C}$-DEPTH135 NMR (175 $\mathrm{MHz}$ in $\mathrm{CDCl}_{3}$ ) analysis of Rh-catalyzed hydroformylation of 1-octene. 
rk-ch-01-conti.13.fid

rk-ch-01-conti

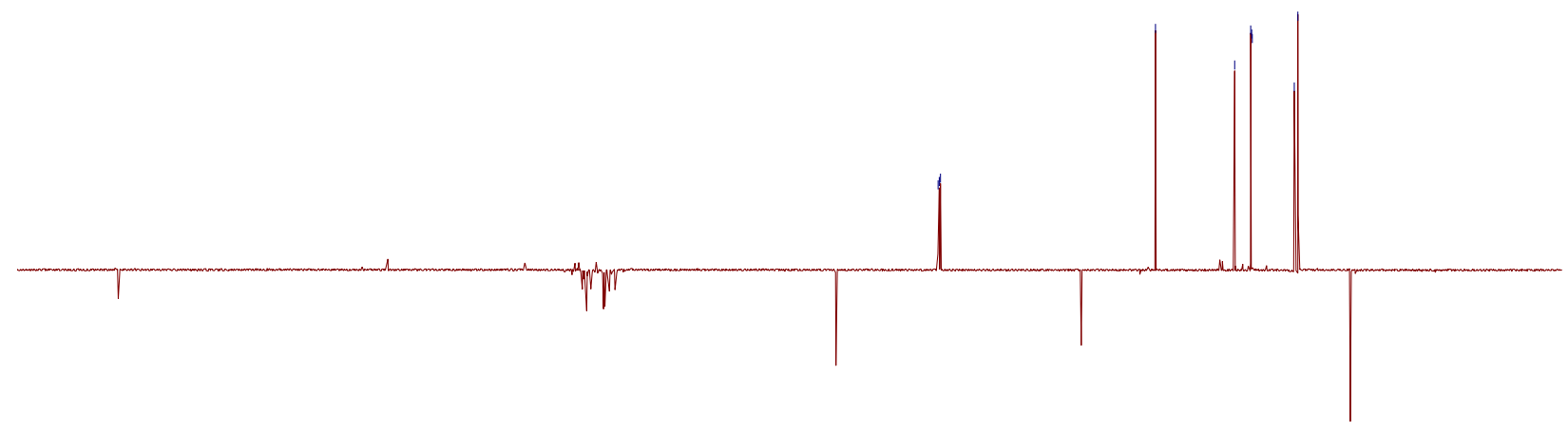

$\begin{array}{lllllllllllllllllllllll}210 & 200 & 190 & 180 & 170 & 160 & 150 & 140 & 130 & 120 & 110 & 100 & 90 & 80 & 70 & 60 & 50 & 40 & 30 & 20 & 10 & 0 & -10\end{array}$

Figure S17: Crude ${ }^{13} \mathrm{C}-\mathrm{APT}$ NMR $\left(175 \mathrm{MHz}\right.$ in $\left.\mathrm{CDCl}_{3}\right)$ analysis of Rh-catalyzed hydroformylation of 1-octene. 

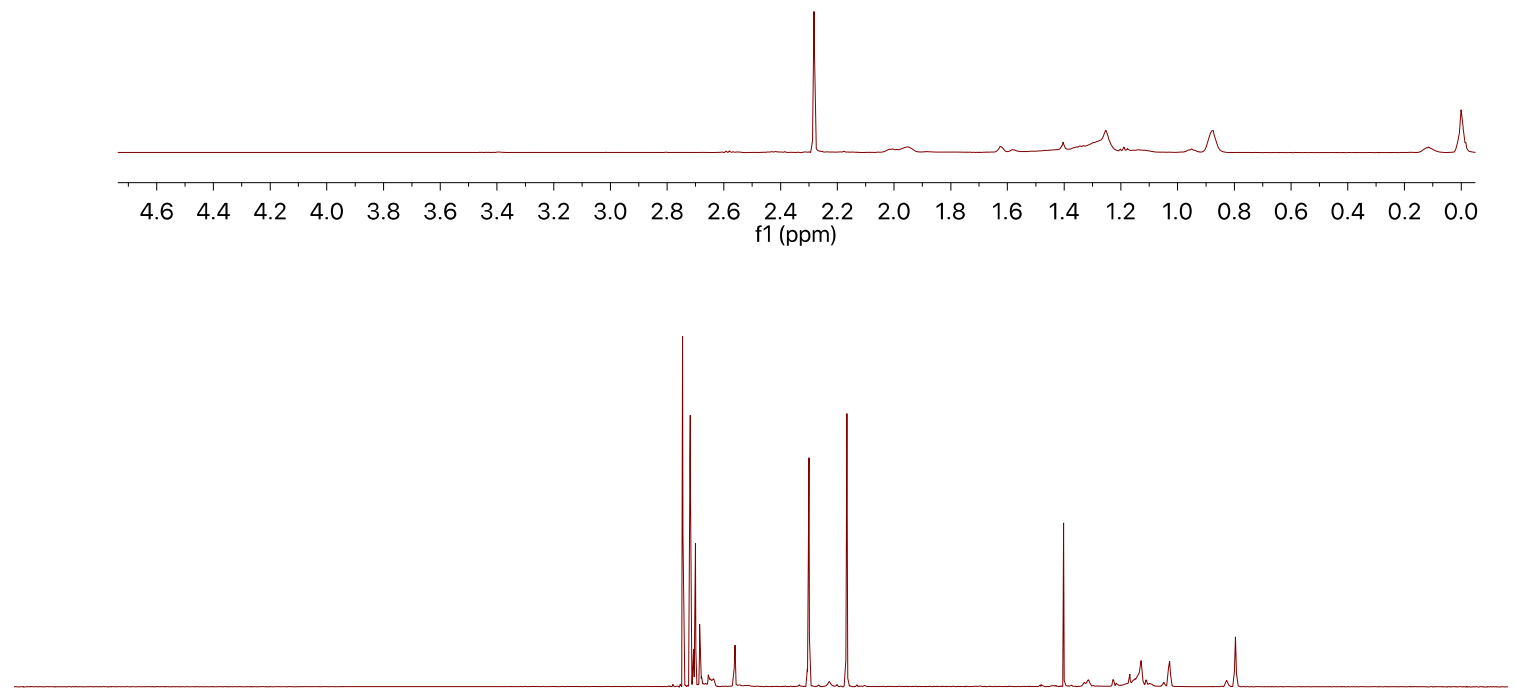

$\begin{array}{llllllllllllllllllll}16 & 15 & 14 & 13 & 12 & 11 & 10 & 9 & 8 & 7 & 6 & 5 & 4 & 3 & 2 & 1 & 0 & -1 & -2 & -3\end{array}$

Figure S18: ${ }^{1} \mathrm{H}$ NMR $\left(700 \mathrm{MHz}\right.$ in $\left.\mathrm{CDCl}_{3}\right)$ analysis of compound 7. 


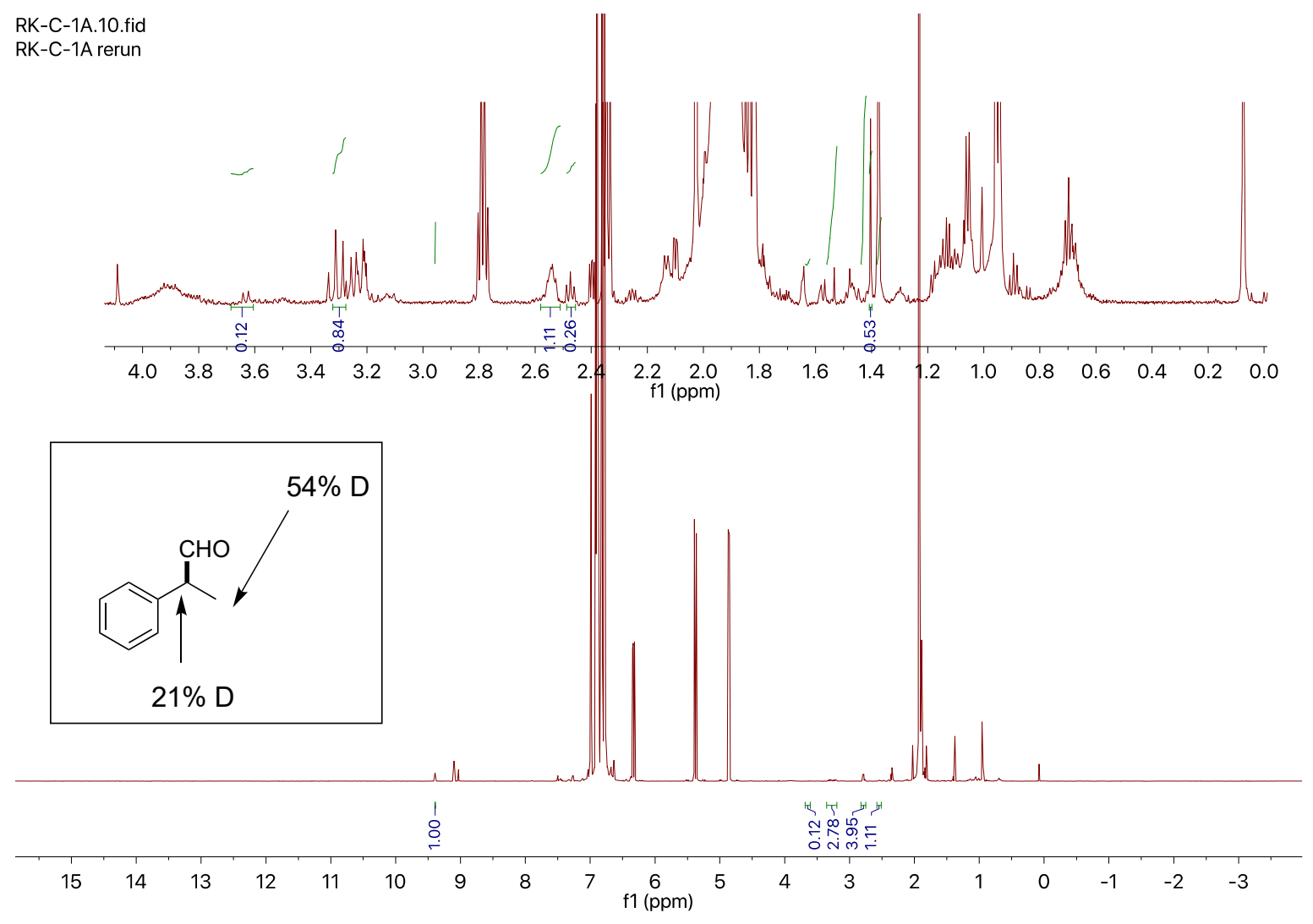

Figure S19: Crude ${ }^{1} \mathrm{H}$ NMR $\left(700 \mathrm{MHz}\right.$ in $\left.\mathrm{CDCl}_{3}\right)$ analysis of compound $\mathbf{8 a}$.

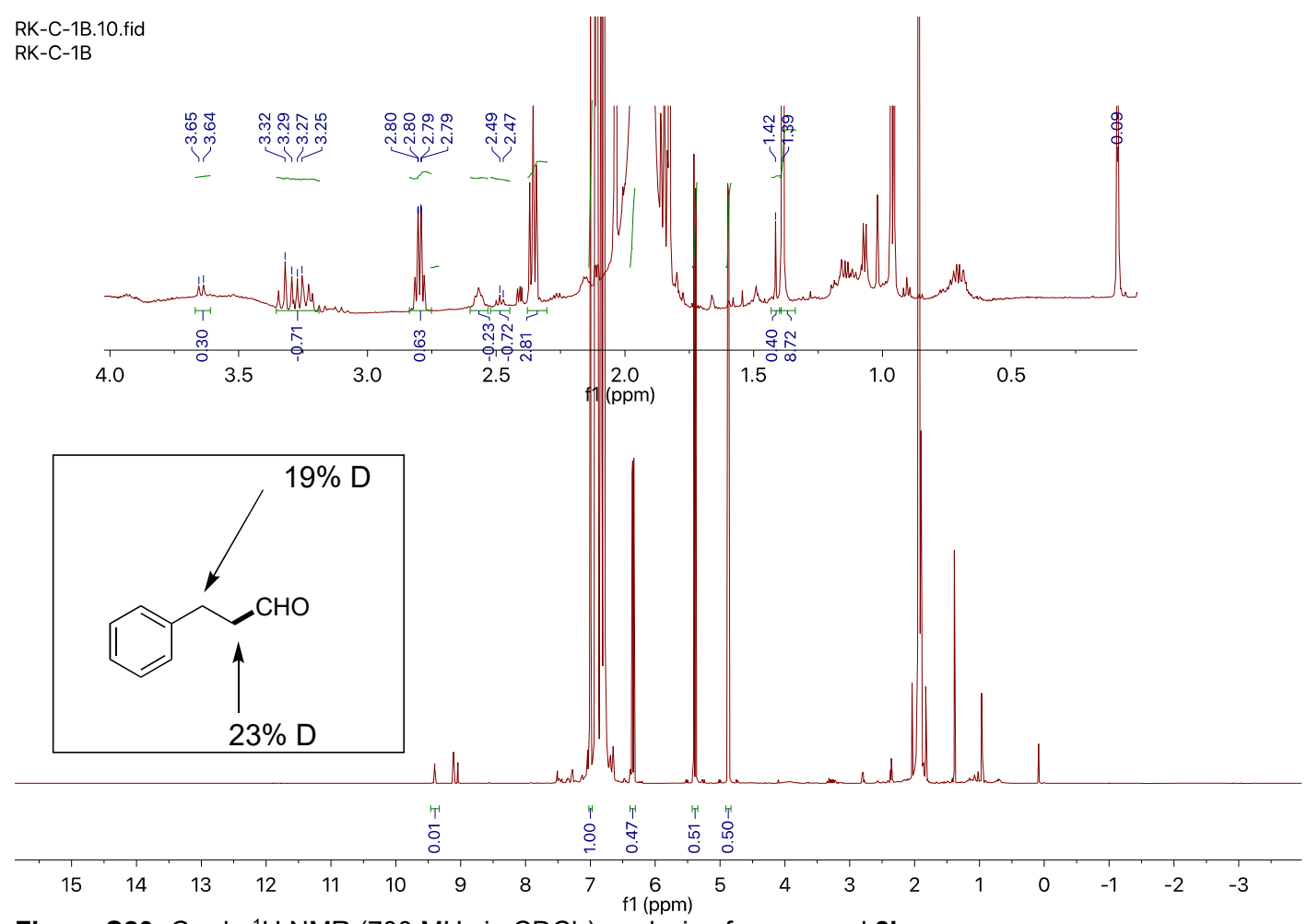

Figure S20: Crude ${ }^{1} \mathrm{H}$ NMR (700 MHz in $\left.\mathrm{CDCl}_{3}\right)$ analysis of compound $\mathbf{8 b}$. 


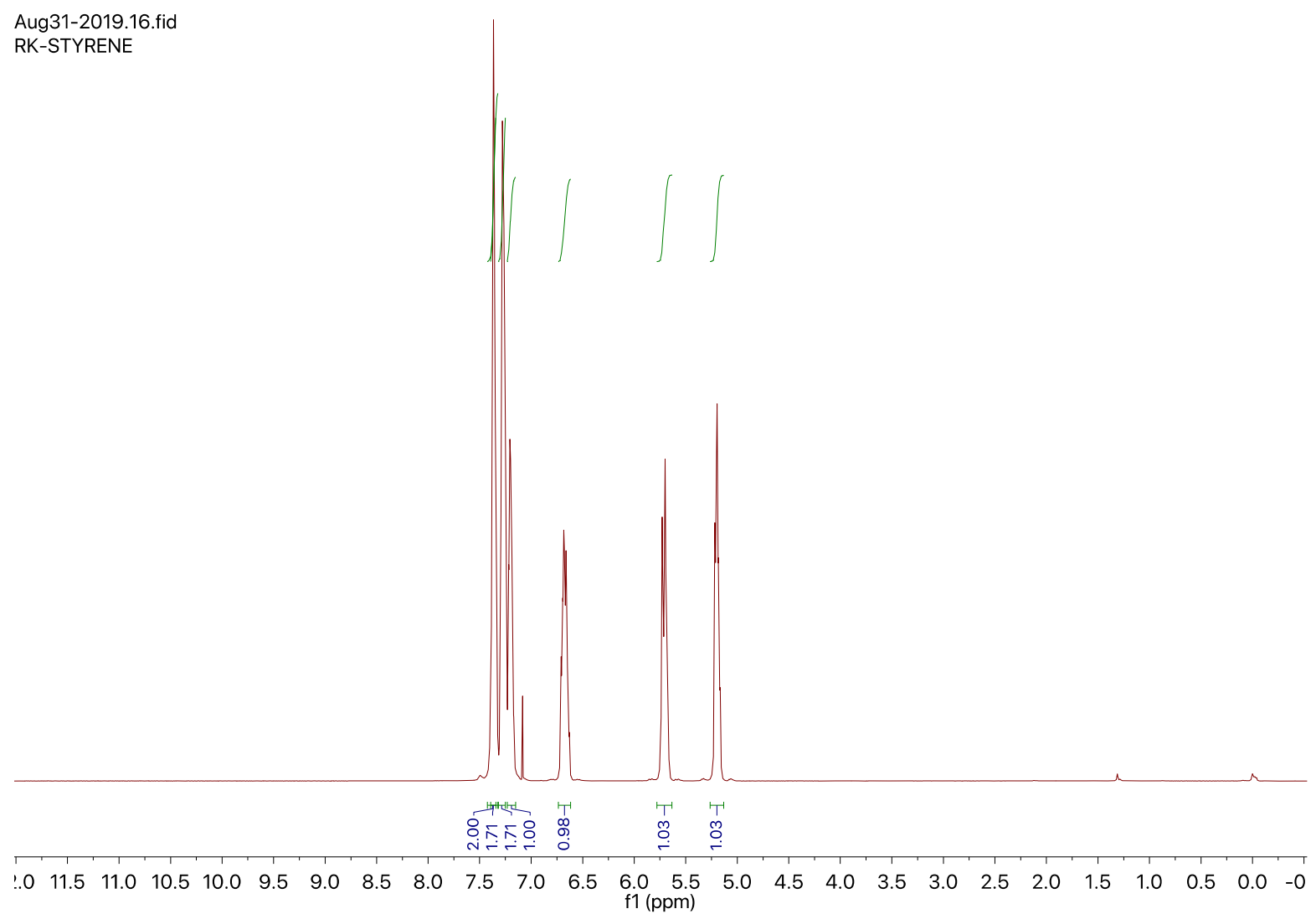

Figure S21: ${ }^{1} \mathrm{H}$ NMR $\left(700 \mathrm{MHz}\right.$ in $\left.\mathrm{CDCl}_{3}\right)$ analysis of purified compound 9. 
Aug31-2019.25.fid

2-PHENYL-PROPANAL

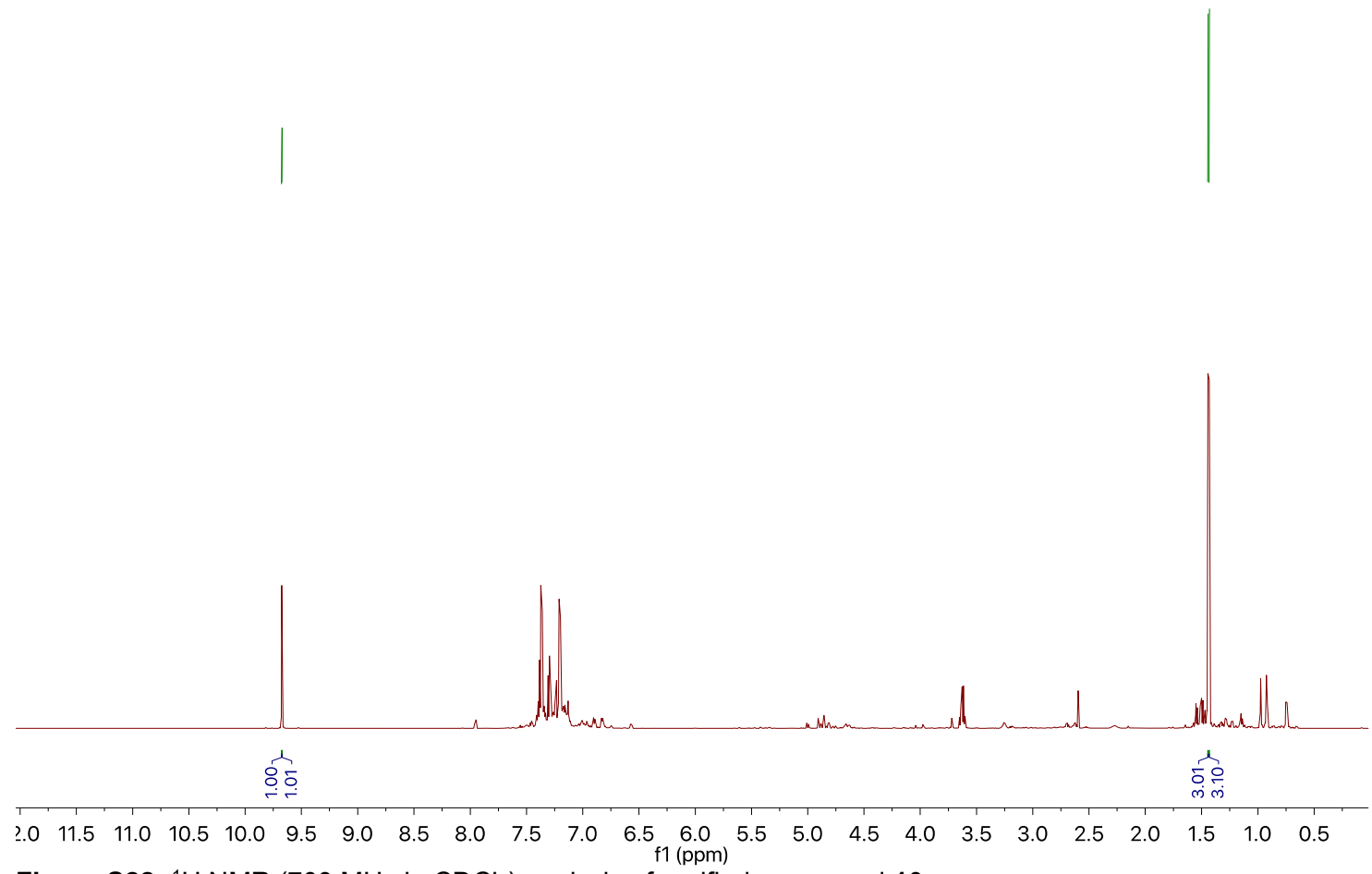

Figure S22: ${ }^{1} \mathrm{H}$ NMR $\left(700 \mathrm{MHz}\right.$ in $\left.\mathrm{CDCl}_{3}\right)$ analysis of purified compound 10a.

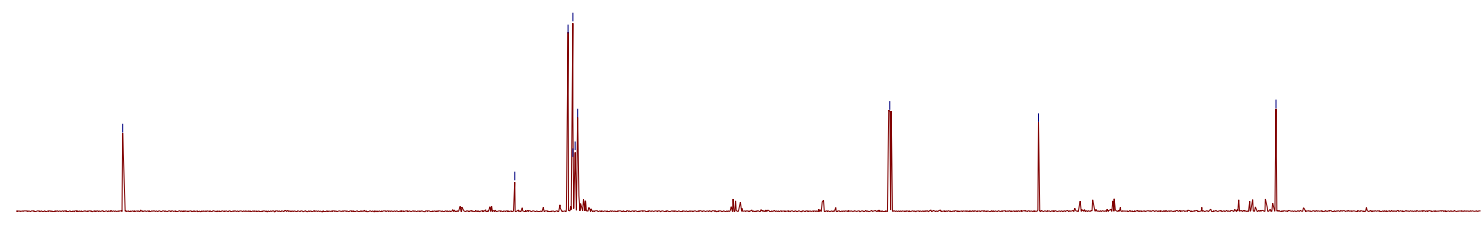

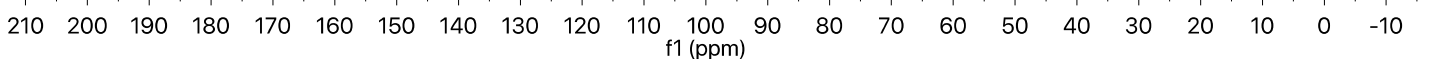

Figure S23: ${ }^{13} \mathrm{C}$ NMR (175 $\mathrm{MHz}$ in $\mathrm{CDCl}_{3}$ ) analysis of purified compound 10a. 


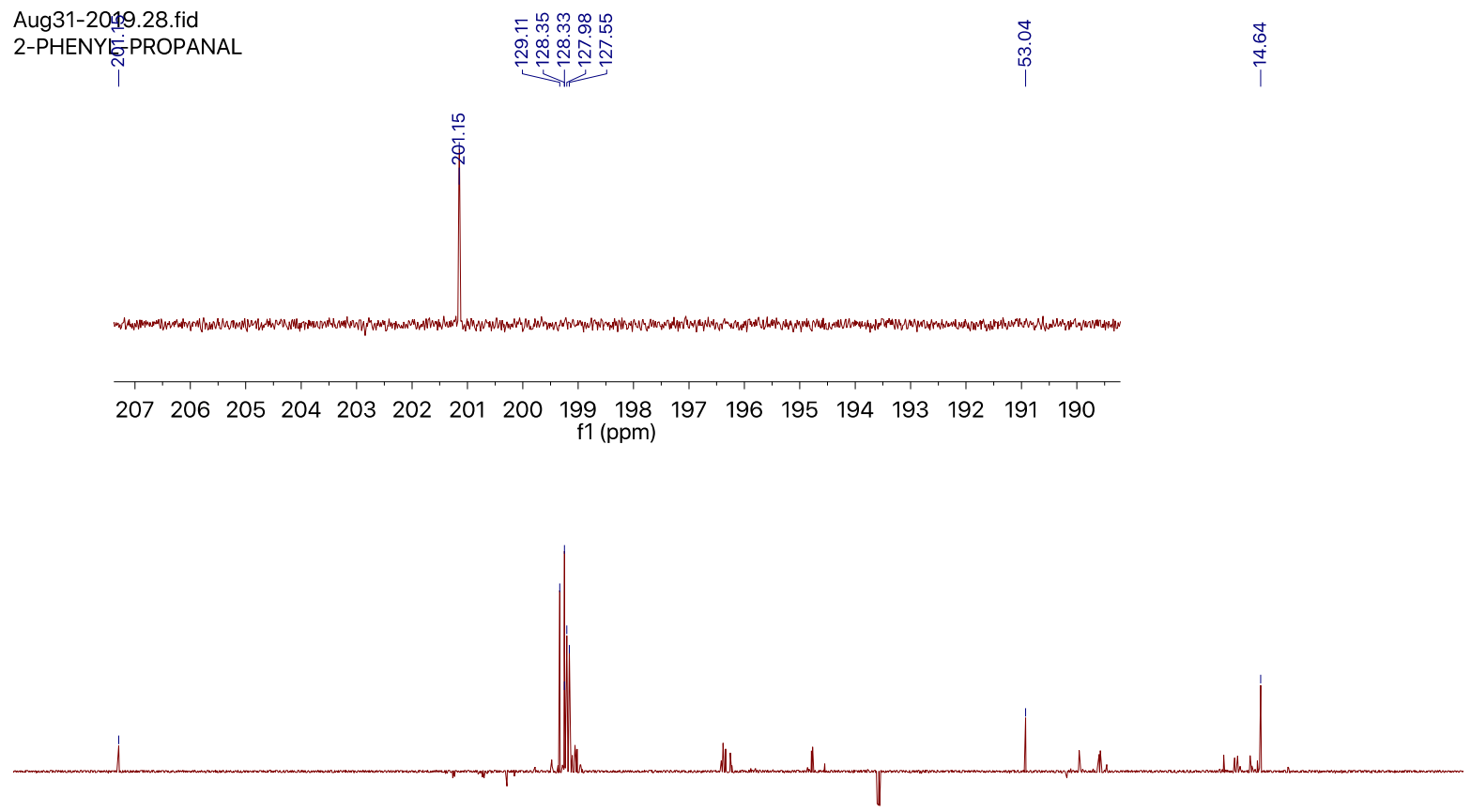

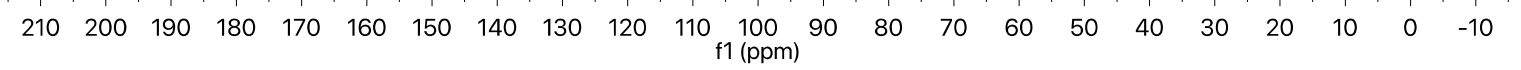

Figure S24: ${ }^{13} \mathrm{C}$ NMR-APT (175 $\mathrm{MHz}$ in $\mathrm{CDCl}_{3}$ ) analysis of purified compound 10a. 


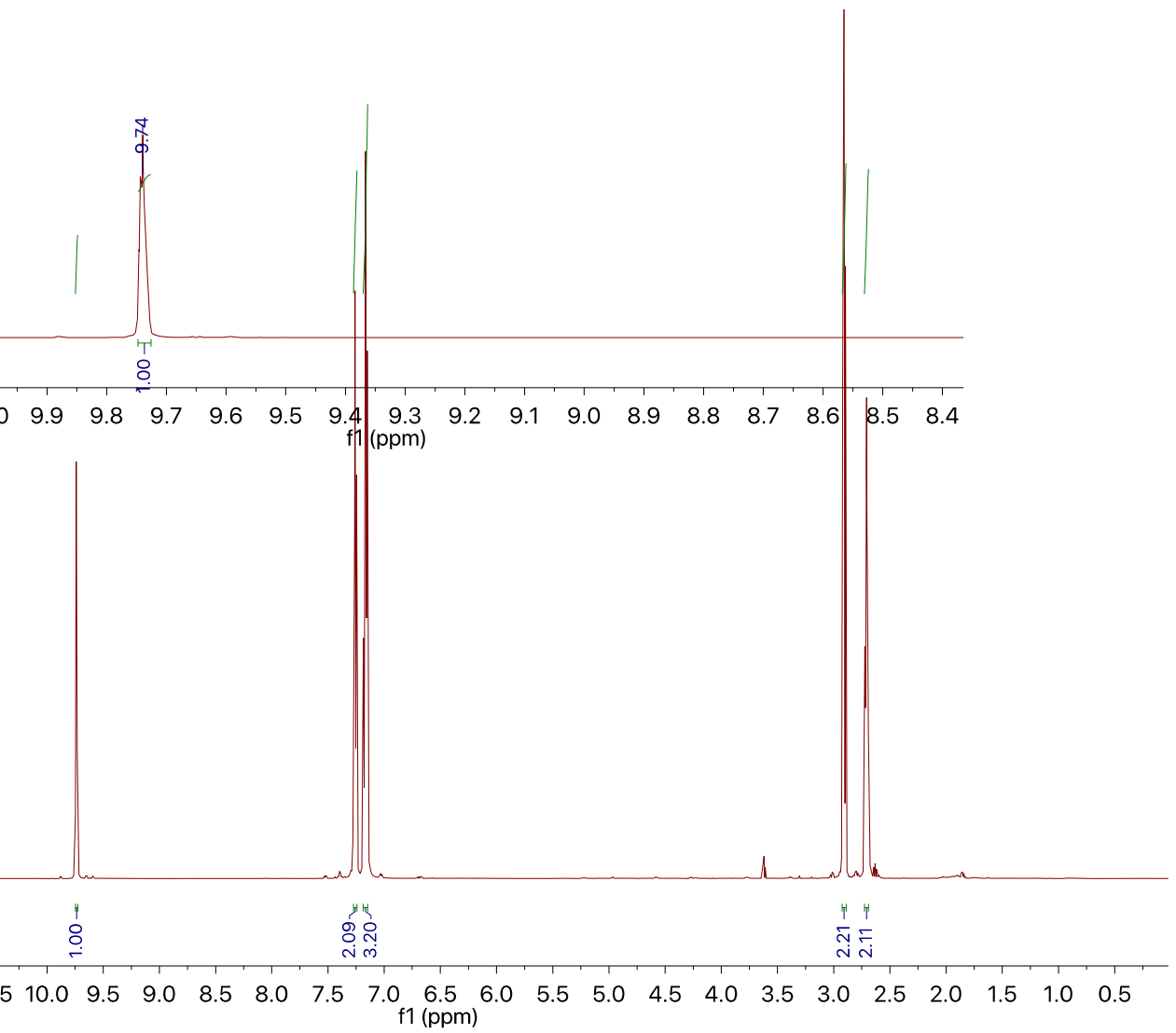

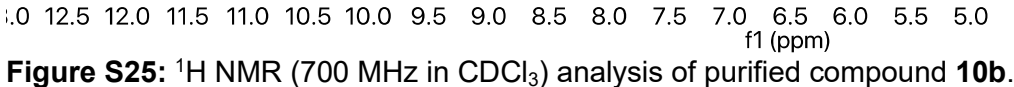




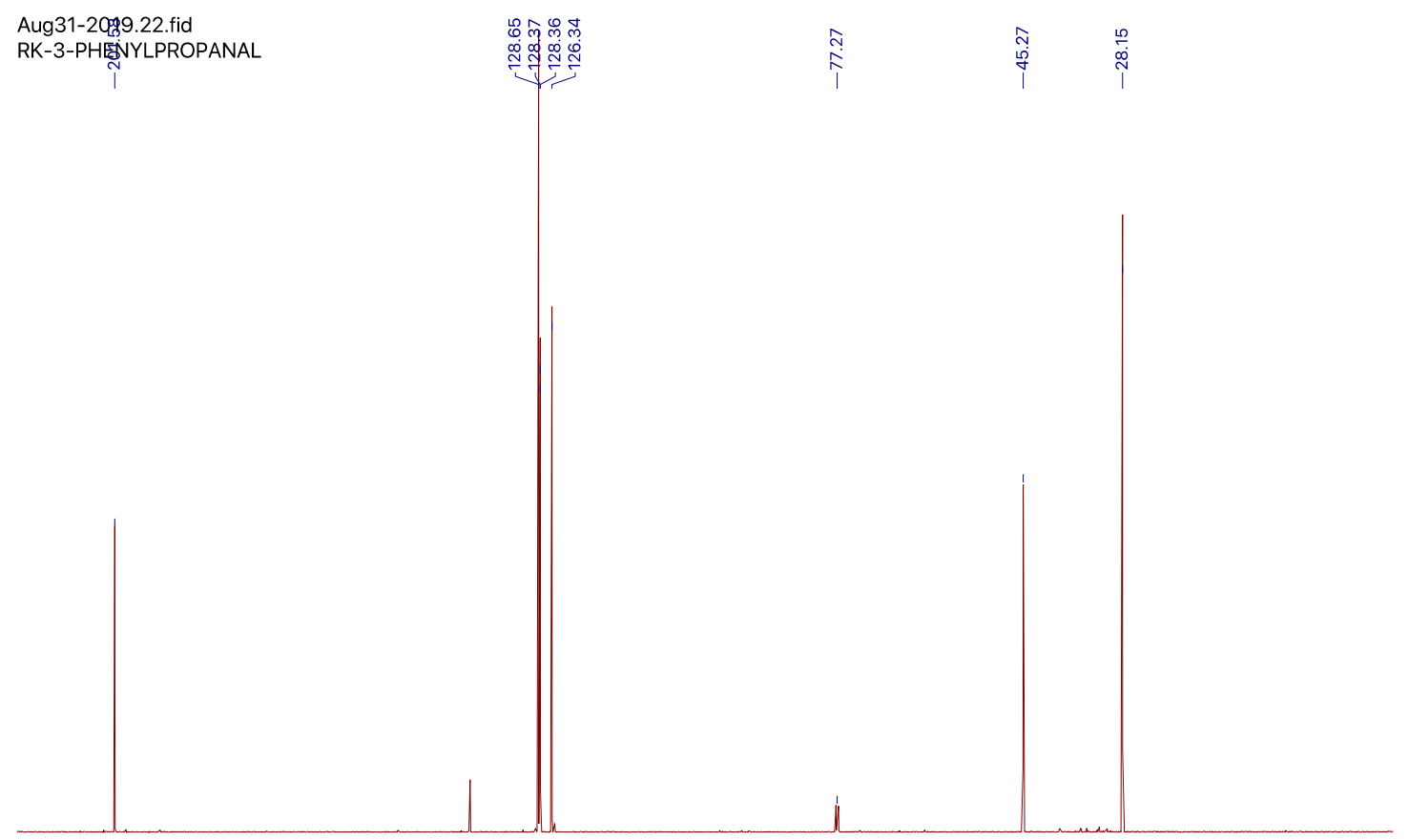

$\begin{array}{llllllllllllllllllllllll}210 & 200 & 190 & 180 & 170 & 160 & 150 & 140 & 130 & 120 & 110 & 100 & 90 & 80 & 70 & 60 & 50 & 40 & 30 & 20 & 10 & 0 & -10\end{array}$

Figure S26: ${ }^{13} \mathrm{C}$ NMR (175 $\mathrm{MHz}$ in $\mathrm{CDCl}_{3}$ ) analysis of purified compound 10b.

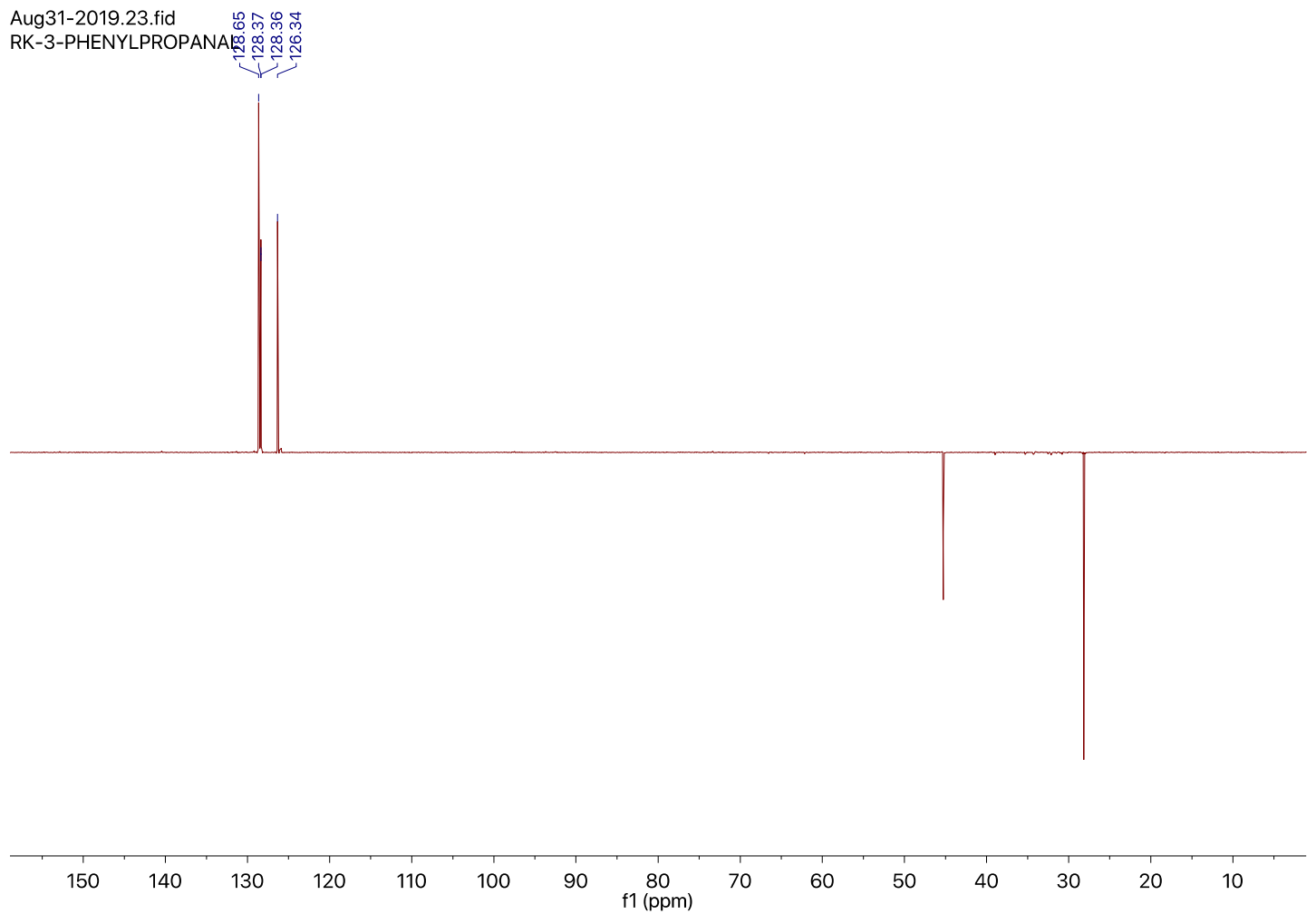

Figure S27: ${ }^{13} \mathrm{C}$ NMR-DEPTH (175 $\mathrm{MHz}$ in $\mathrm{CDCl}_{3}$ ) analysis of purified compound 10b. 


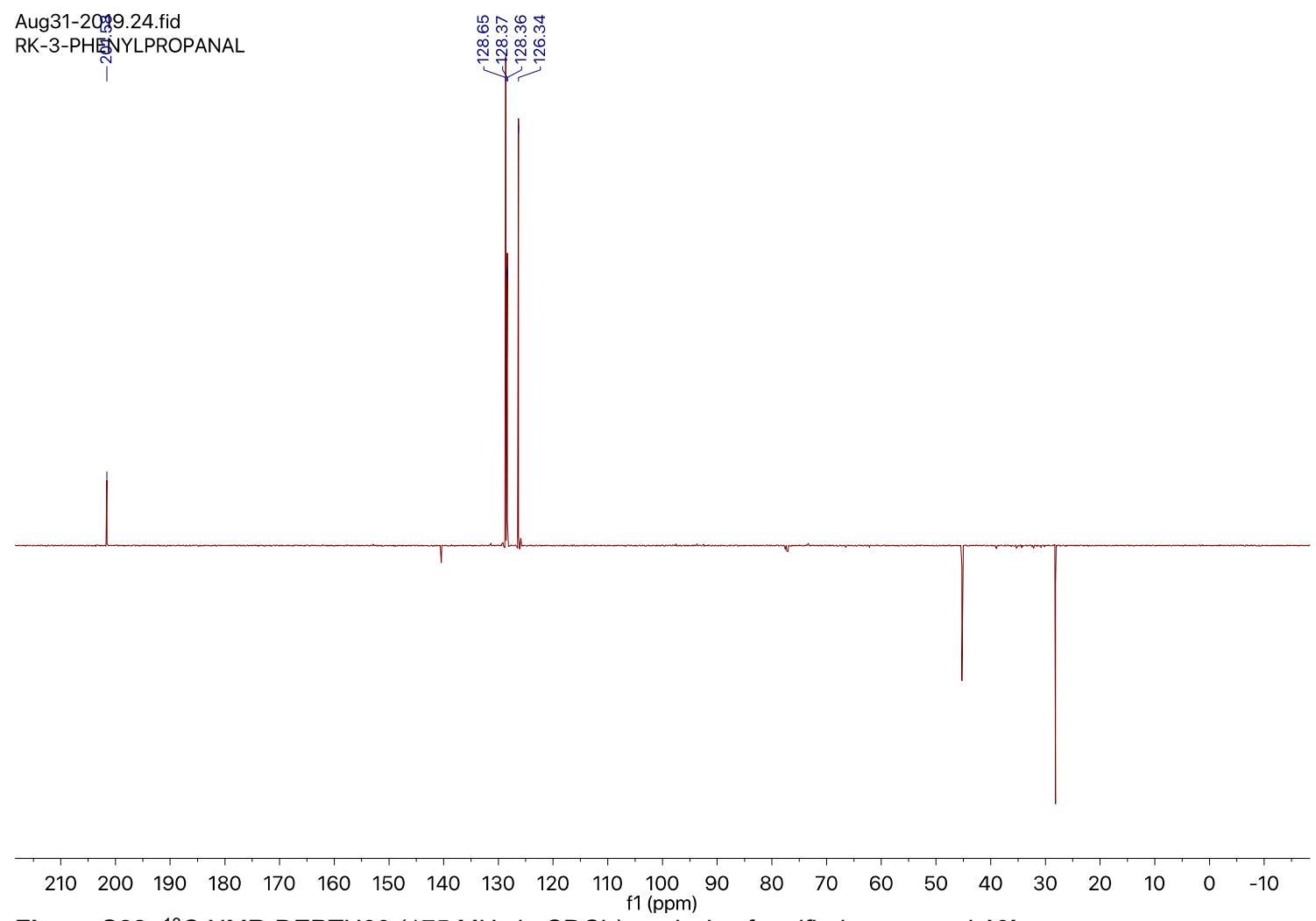

Figure S28: ${ }^{13} \mathrm{C}$ NMR-DEPTH90 (175 $\mathrm{MHz}$ in $\mathrm{CDCl}_{3}$ ) analysis of purified compound $10 \mathbf{b}$. 


\section{S5. References.}

1. Zhu, C.; Raghuvanshi, K.; Coley, C. W.; Mason, D.; Rodgers, J.; Janka, M. E.; Abolhasani, M. Flow Chemistry-Enabled Studies of Rhodium-Catalyzed Hydroformylation Reactions. Chem. Commun. 2018, 62, 8567-8570.

2. Abolhasani, M.; Coley, C. W.; Jensen, K. F. Multiphase Oscillatory Flow Strategy for in Situ Measurement and Screening of Partition Coefficients. Anal. Chem. 2015, 21, 11130 11136.

3. Dingwall, P.; Fuentes, J. A.; Crawford, L.; Slawin, A. M. Z.; Bühl, M.; Clarke, M. L. Understanding a Hydroformylation Catalyst That Produces Branched Aldehydes from Alkyl Alkenes. J. Am. Chem. Soc. 2017, 44, 15921-15932. 